Bellón Climent, Antonio. Las fiestas de la "Mare de Déu de la Salut" de Algemesí (Valencia): una tradición convertida en Patrimonio Inmaterial de la Humanidad. GeoGraphos [En línea]. Alicante: Grupo Interdisciplinario de Estudios Críticos y de América Latina (GIECRYAL) de la Universidad de Alicante, 2 de marzo de 2015, vol. 6, $\mathrm{n}^{\mathrm{o}}$ 75, p. 52-81. [ISSN: 2173-1276] [DL: A 371-2013] [DOI: 1014198GEOGRA2015.6.75].

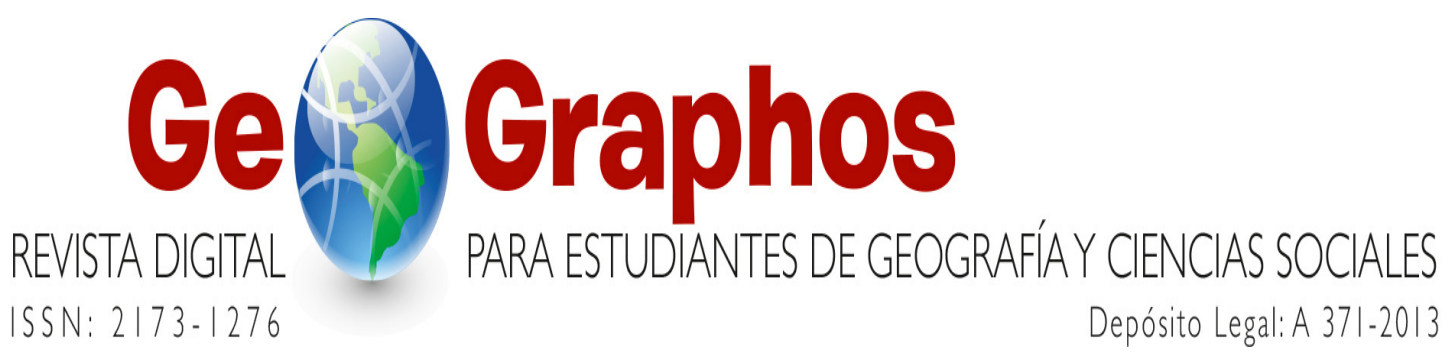

$<$ http://web.ua.es/revista-geographos-giecryal $>$

Vol. 6. $\mathrm{N}^{\mathrm{o}} 75$

Año 2015

\title{
LAS FIESTAS DE LA "MARE DE DÉU DE LA SALUT" DE ALGEMESÍ (VALENCIA): UNA TRADICIÓN CONVERTIDA EN PATRIMONIO INMATERIAL DE LA HUMANIDAD
}

\author{
Antonio Bellón Climent \\ Grado en Geografía y Ordenación del Territorio \\ Facultad de Filosofía y Letras. Universidad de Alicante (Alicante, España) \\ Correo electrónico: abc59@alu.ua.es
}

Recibido: 22 de mayo de 2014. Devuelto para revisión: 14 de noviembre de 2014. Aceptado: 2 de marzo de 2015

\section{RESUMEN}

En el siguiente trabajo se investigarán las fiestas locales del municipio de Algemesí, que se celebran los días 7 y 8 de septiembre, y que se han convertido en una celebración centenaria gracias al mantenimiento, continuidad y potenciación de los elementos que la forman, y que tras una serie de reconocimientos por parte de diferentes organismos e 
instituciones que comenzaron en 1977, con la declaración como Bien de Interés Turístico, en los últimos cinco años ha venido recibiendo un reconocimiento detrás de otro, hasta que en el año 2011 fue declarado Patrimonio Inmaterial de la Humanidad por la UNESCO. Esta tradición guarda sus raíces en época bajo medieval, pues en el año 1247 se produjo la "troballa" de la imagen de la virgen en una morera, situada según la teoría más aceptada donde se levantó la Capella de la Troballa.

Palabras clave: Patrimonio Inmaterial de la Humanidad, Algemesí, muixeranga, Mare de Déu de la Salut, procesión, dolçaina y tabalet.

\title{
THE MARE DE DÉU DE SALUT FROM ALGEMESI PARTIES: A TRADITION TURNED INTO INTANGIBLE HERITAGE OF HUMANITY
}

\begin{abstract}
In the following project, the local festivities of the municipality of Algemesí, celebrated on 7 and 8 September have been investigated, and they have become a centennial celebration thanks to the maintenance, continuity and strengthening of the elements forming it. After a number of awards given by various organizations and institutions that began in 1977 with the Declaration as well tourist attractions, in the last five years, it has received one recognition after another, until in the year 2011 it was declared Intangible Cultural Heritage of Humanity by UNESCO. This tradition has its roots at medieval times, because in the year 1247 the image of the Virgin was found in a mulberry (this is calle "troballa" in Valencian language), located, according to the most accepted theory where the Capella de la Troballa was built.
\end{abstract}

Key words: Intangible Heritage of the Humanity, Algemesí, muixeranga, Mare de Déu de la Salut, procession, dolçaina and tabalet.

\section{O MARE DE DEU DE SALUT ALGEMESI PARTES: UMA TRADICÃO SE TRANSFORMOU EM PATRIMONIO IMATERIAL DA HUMANIDADE}

\section{RESUMO}

No trabalho seguinte partes investigadas localea ao municipio de Algemesí, celebrado nos días 7 e 8 de setembro, e que se tornaram um centenario graças a manutenção, continuidade e reforço dos elementos formando-lo e depois de uma série de prêmios por varias organizaçoes e instituições que se iniciou em 1977 com a declaração também atrações turísticas, nos últimos cinco anos tem recebido reconhecimento atrás du outro, até o ano de 2011 foi declarado Patrimonio Cultural Imaterial da Humanidade pela UNESCO. Esta tradição mantém suas raízes no tempo sob medieval, porque no ano de 1247 veio a "troballa" da imagen da virgen em uma amoreira, localizada de acordó com a teoria mais aceita onde rosa a Capella de la Troballa.

Palavras-chave: Patrimonio Imaterial da Humanidade, Algemesí, muixeranga, Mare de Déu de la Salut, procissão, dolçaina e tabalet. 


\section{INTRODUCCIÓN}

Esta celebración tiene su origen, en 1247, cuando según la tradición oral (pues no existe documentación), en una morera situada en la actual Plaça del Pouet, que tenía un hueco en su tronco, se produjo la "troballa", pues un vecino se encontró una escultura exenta de una virgen. Este hecho guarda relación a que tras la reconquista, se expulsó a los pobladores musulmanes locales, y se repobló con gente cristiana, y se produjo la necesidad de fortalecer esta religión en estas tierras

Aunque realmente la festividad abarca el periodo que se inicia a partir del 29 de agosto cuando comienza la "Novena" (que finaliza el 6 de septiembre), en esta obra se estudiarán principalmente las tres procesiones que se realizan en los días 7 y 8 de septiembre. También se analizará la repercusión que ha tenido esta fiesta más allá de las fronteras del propio municipio y de todos los reconocimientos que ha recibido. Uno de los elementos más destacados es que prácticamente toda la población de la localidad, participa de forma activa o pasiva en ésta. De forma activa o bien formando parte de alguna danza, grupo de música, siendo portador del anda de la Mare de Déu de la Salut, participando en la Processó de les Promeses, los festeros a los que les corresponde ese año dirigir la fiesta, los eclesiásticos, o los miembros de Protección Civil, o bien toda la gente que colabora de alguna forma a lo largo del año en la preparación, las personas creyentes que acuden a los actos religiosos relacionados con esta celebración, los residentes en los carrers de volta que engalana sus balcones y que abren sus puertas para la llegada de invitados, etc. Y de forma pasiva todas las personas que acuden a ver alguna de las tres procesiones. Debido a que esta alquería hasta 1574 estuvo sujeta administrativamente a Alcira, la escultura fue llevada tres veces a esta ciudad, pero cuenta la tradición que tantas volvió a aparecer en la morera. Este hecho se conmemora con la "Nit del Retorn", que en esta investigación no se analizará, y también en cada "entrada" de la figura de la virgen tras su recorrido por las calles, con la acción simbólica de entrar y salir tres veces.

El municipio de Algemesí cuenta con 28.000 habitantes, y se encuentra situado en la provincia de Valencia, en la comarca de la Ribera Alta, cuatro kilómetros al norte de Alcira. La superficie que comprende el término municipal es de $41^{\prime} 5 \mathrm{~km}^{2}$, de los cuales $33^{\prime} 9 \mathrm{~km}^{2}$ se destinan a actividades agrícolas, siendo en la actualidad una ciudad agroindustrial, donde predomina el cultivo de cítricos (naranjos y mandarinos), desde hace aproximadamente siglo y medio. En cuanto a las comunicaciones existe buena accesibilidad tanto por carretera como por ferrocarril. Por el término municipal discurre la AP-7, teniendo una salida, aunque queda lejos del casco urbano, y que para llegar a éste tras salir de ésta se ha de entrar por la CV-42. También se puede llegar a través de la CV-525 tras partir de la A-7 por Alginet. Otro medio para llegar, es el ferrocarril, pues no en vano en el municipio hay estación, que no es parada para los trenes que hacen trayectos de media y larga distancia, pero sí para las líneas de cercanías. Un punto a favor para venir con este último medio de transporte es que ésta se encuentra muy cerca del escenario de la fiesta.

Este estudio se ha realizado a través de dos metodologías. Para comenzar se han consultado diversas bibliografías, la gran mayoría de ellas de autores de esta localidad. Tras esto se ha realizado la técnica cualitativa de trabajo de campo. En cuanto a las técnicas utilizadas en esta última, se han hecho una serie de entrevistas, destacando la realizada a Julio Blasco, director del Museu Valencia de la Festa, pues es una de las personas con mayor conocimiento de esta celebración y su organización. 


\section{LOS ELEMENTOS DE LA FIESTA}

Esta tradición consiste en la celebración de tres procesiones, que se realizan a través de tres recorridos que tienen una fuerte identidad para la población local. La fiesta está formada por una serie de elementos, que son las diferentes danzas que actúan, la música que acompaña a éstas, realizada con tabal y dulzaina, los aspectos religiosos que aparecen y el sonido de las campanas.

\section{Las danzas y el Tabalet y la Dolçaina}

Existe una interrelación entre las danzas y la música. Las primeras, en un principio eran subsidiarias a la procesión pero luego pasaron a tener un carácter independiente. Cada una es autónoma, actuando y ensayando por su cuenta. Todas las personas que participan en una de ellas se pagan su vestimenta, por tanto existe un gasto individual. Tampoco se cobra por actuar en las procesiones. Éstas no solo actúan el 7 y 8 de septiembre, sino que ensayan a lo largo de todo el año, ya que es habitual que algunos de ellas viajen para actuar en otros lugares, tanto de la Comunidad Valenciana como en otras partes de la geografía española, e incluso internacional. En cuanto al elemento más singular de la música, es que exceptuando Tornejants y Llauradores, todas actúan al son del tabalet y dolçaina.

\section{La Muixeranga d'Algemesí y La Nova Muixeranga}

Su primera documentación aparece en 1733. Es el principal embajador de Algemesí, y uno de los elementos más representativos de la cultura valenciana. Pero no siempre fue así, pues esta manifestación vivió un proceso de devaluación desde la segunda mitad de siglo XX, con un déficit de miembros y la baja condición social de éstos. Además no era un grupo fijo, pues no superaba las 30 personas. Hasta que en 1973 tocó fondo, cuando dejó de actuar en la Processó de les Promeses y en la Processoneta del Matí, tras las disputas entre sus componentes y los festeros. Pero gracias a la decisión de 30 personas, que salieron en la procesión de la noche, esta tradición no desapareció. Este hecho marcó un punto de inflexión, a partir del cual la fiesta fue en auge, en gran parte por el impulso de su danza más representativa, que se ha convertido en el símbolo de ésta. Comenzó a resurgir y poco a poco a crecer en popularidad y prestigio, hasta llegar a ser lo que es hoy, «convertint-se en orgull i bandera de la població» (Alcaraz, 2004, p. 25). Pero el aspecto que más valor le da a esta manifestación y del que no puede presumir ningún otro grupo de representaciones similares, es su aparición de forma continua sin ninguna interrupción en el tiempo, desde su aparición como elemento de las fiestas patronales. En la actualidad está formada por dos conjuntos: la Muixeranga d'Algemesí (en adelante la "Blava") y la Nova Muixeranga (en adelante la "Verda").

En cuanto a sus figuras ${ }^{1}$, cabe destacar tres categorías: el baile, las torres humanas y los cuadros plásticos. La primera de ellas, no se realiza en altura, sino que de manera individual los muixeranguers se ponen en dos filas portando un cirio en la mano realizando una serie de movimientos. La melodía que acompaña esta actuación es Florete. Las figuras plásticas son las representaciones simbólicas, es decir las que tienen un carácter religioso. Las torres son las representaciones construidas en altura. La estructura de éstas está compuesta por tres elementos: la base, los pisos y la piña. El primero son los que sostienen el conjunto elevado en altura. La piña todos los que 
apoyan la base. Los pisos son cada uno de los eslabones humanos en la vertical, siendo conocido al miembro que realiza el penúltimo como el "alçador", y sobre sus hombros, como coronación sostiene al "xiquet". Este último extiende los dos brazos, y a veces también una pierna. Esto resulta una de las imágenes más representativas. Su realización viene acompañada de la melodía La Muixeranga. Cada uno de los dos grupos tiene un mestre, que es quién dirige.

$\mathrm{Su}$ vestimenta está formada por un uniforme hecho con tela de colchón, con franjas verticales rojas, azules y blancas, en el caso de la "Blava", y rojas, verdes y blancas, en el de la "Verda", tanto en la parte superior como en el pantalón. El cuerpo esta botonado por la parte delantera. Llevan un gorro con orejas, también con las franjas. Una característica es que las rayas de la parte del tronco no coinciden con las del pantalón. Quizás la razón de la utilización de esta materia, es porque ésta es dura y resistente, y ello impide que durante la realización de las diferentes construcciones no sea rasgada con los agarrones.

Es una danza que tiene una enorme ritualización a lo largo del itinerario. Comienza con el "Ball". Luego se realiza "l'Alta", que es la torre más característica, y puede ser de cinco o seis pisos. Durante las procesiones es habitual montar la "Marieta". En ésta mediante una construcción de dos alturas, y con un cuatro muixeranguers por encima de la base sostienen y levantan al bebe, realizando su "bautizo". Representa la ascensión de la virgen. Normalmente cuando se hace esta figura y cogen a un lactante, cuando lo bajan no desmontan, sino que van subiendo a más. También en algunas torres, al xiquet a veces lo cogen desde algún balcón. Uno de los cuadros simbólicos más curiosos es L'Enterro, que se realiza acompañada de la melodía Dis Irae. Una de las representaciones plásticas más emblemáticas es el "Altar", que es la que se realiza por ejemplo en la "entrada de la Mare de Déu", montándose a ambos lados.

\section{Fotografía 1. La Blava realizando L'Alta de 6 delante del Ayuntamiento}

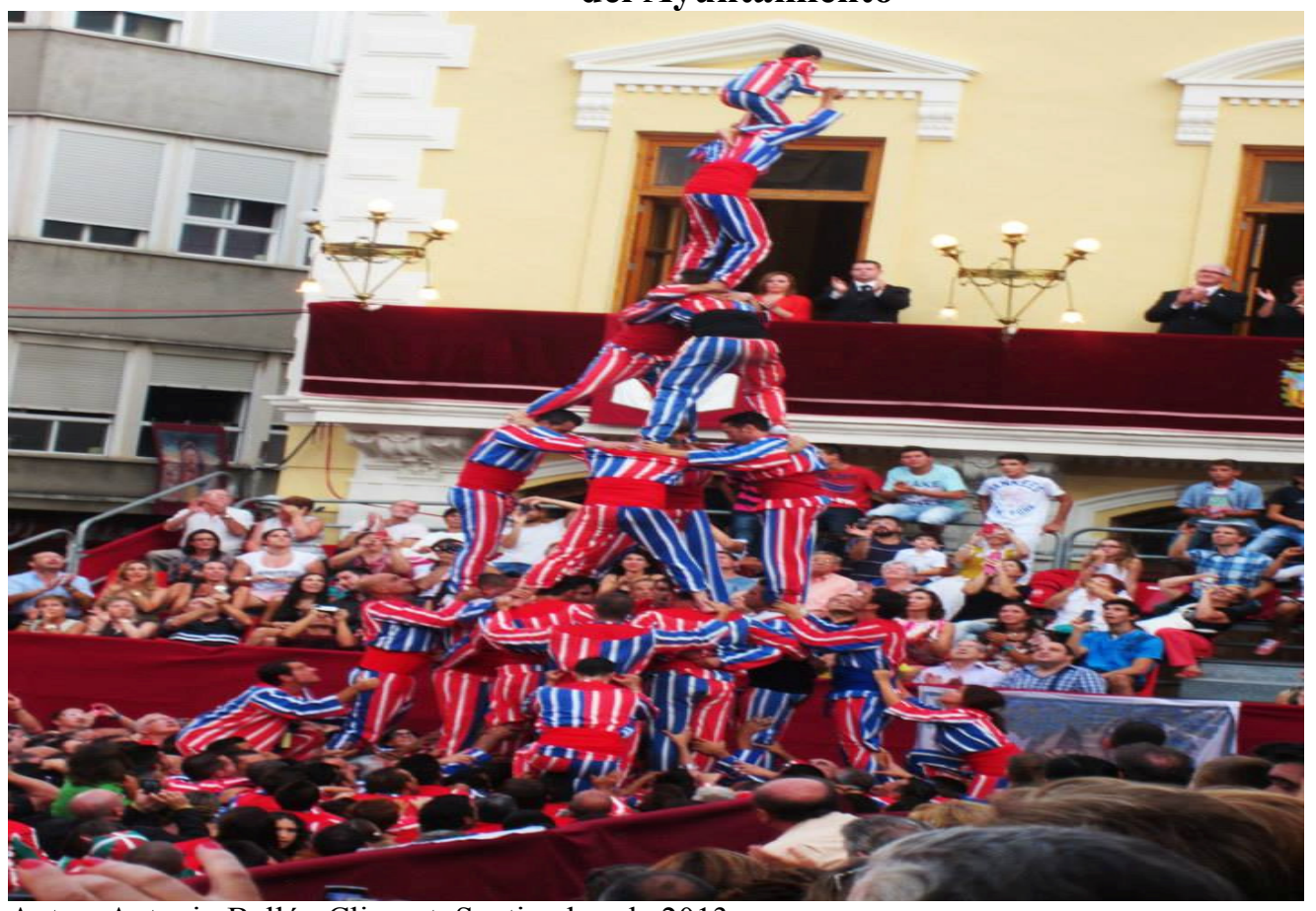

Autor: Antonio Bellón Climent. Septiembre de 2013. 
Las salidas de la "Blava" han sido numerosas, no solo en territorio valenciano, sino en todo el territorio nacional, y traspasando las fronteras nacionales. Entre éstas cabe destacar las numerosas visitas a tierras catalanas, y a Madrid como representante de las Fiestas de la Mare de Déu de la Salut en FITUR. Pero quizá su actuación más singular ha sido cuando tras su viaje a Bruselas, se le puso un vestido de "xiquet" a la estatua del Manneken Pis, uno de los hitos de esta ciudad. La indumentaria fue donada al museo homónimo, y desde entonces cada 7 y 8 de septiembre se le vuelve a poner.

Debido a la negativa a la entrada de la mujer a entrar a formar parte de la "Blava", cabe destacar el surgimiento en 1997 de una nueva asociación, La Nova Muixeranga, que tiene como principal característica, el elevado número de mujeres que forman parte de ella ${ }^{2}$. Otro aspecto que la diferencia de la otra asociación es la utilización de casco por el "xiquet". Como elemento que refuerza la importancia del elemento femenino, es que tuvo una mestra, Ester Ferrer. Esta asociación tiene mucha menos gente que la otra. Han introducido nuevas figuras como "la Trobada" y han recuperado otras tradicionales como "L'Aranya". Tiene una revista trimestral denominada La Figuereta, que realizó su primer número 2002, y hasta la fecha ha tenido 36 publicaciones. También desde 2009 organiza unas jornadas culturales anuales, llamadas La Muixerola. En el año 1998 recibió la distinción de la Federación de Mujeres Progresistas del País Valenciano.

\section{Els Bastonets}

Es una danza guerrera que para su realización necesita ocho personas, y se hace con un palo y una plancha. El baile consiste en una serie de movimientos, en los que van dando golpes unos miembros a otros con sus armas. El bastón tiene aproximadamente 50 centímetros de longitud. Éste va con una cuerda, que se la atan a la muñeca para que este no se les vaya. La plancha tiene forma redonda. Hace falta una coordinación extraordinaria para hacer estas coreografías, pues van cambiando de compañero al que hay que "golpear", y se realizan de manera muy rápida y se dan con fuerza.

Aparece documentada en 1839. Tiene un origen de danza de clase baja, pues la formaban campesinos. Antes solo actuaban hombres. En 1980, se creó un grupo formado por mujeres. En la actualidad hay dos grupos masculinos y uno femenino. Van «ataviados con una especie de uniforme romano» (Atienza, 1991, p. 2), con cuerpo y faldellín, calzas blancas y alpargata de esparto con vetas negras que atadas sobre las calzas, cada sexo presentando un color diferente en su vestimenta. Los varones van de rojo y las féminas de azul. En la espalda cada uno lleva un motivo mariano diferente. En la cabeza llevan un gorro con plumas.

Tiene 21 melodías distintas, y tantos bailes diferentes. Muchos de ellos son parecidos. Algunos se hacen solamente con palos, y otros combinados con las planchas. Requieren un gran esfuerzo físico. Es habitual que a personas de entre el público que fueron miembros de la danza, les dejen participar en algunas coreografías.

\footnotetext{
${ }^{1}$ Para ver y obtener información más detallada sobre las figuras que realizan actualmente ambos grupos de Algemesí, consultar las páginas webs de la "Blava" y la "Verda" disponibles en: http://www.muixeranga.net/ y http://www.novamuixeranga.com/.

2 Actualmente la mujer también participa en la "Blava". Su entrada se produjo hace una década.
} 


\section{Fotografía 2. El grupo femenino de los Bastonets actuando en la Plaça Major}

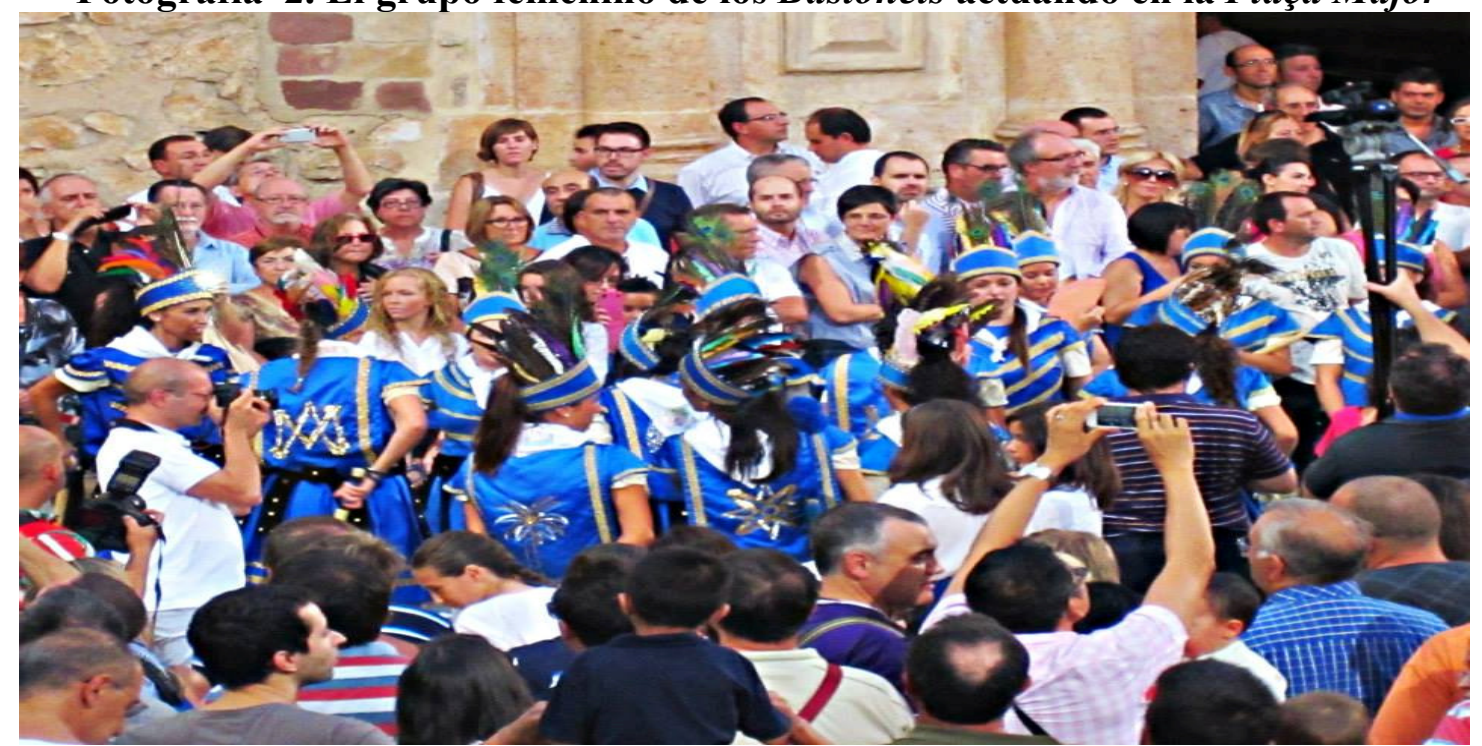

Autor: Antonio Bellón Climent. Septiembre de 2013.

Uno de los bailes más representativos es "la Fuga", que destaca por empezar muy lento, y progresivamente va aumentando su ritmo, para acabar muy rápido y enérgico. " $L a$ Corredora" es trepidante desde su inicio. "L'U" es la que se suele hacer en la entrada de la Mare de Déu en la Processoneta del Matí. "La Gallega" es característica por el grito que realizan. El "Altar" lo realizan solo delante de las cerámicas marianas. Es muy llamativa porque es la melodía l' $U$, pero a mitad de ésta suena La Muixeranga, y en un momento dado se arrodillan todos los bailadores frente al retablo, para después seguir con la coreografía. "La Figuera" es lenta, y es habitual que alguno de los miembros lleve un bebé en brazos.

\section{Les Pastoretes, el Ball de la Carxofa i els Arquets}

Las tres proceden del Corpus Christi. La primera aparece documentada en 1834. Actualmente de carácter mixto, desde que en 1972 se incorpora al niño en la danza, por decisión de María Vendrell, que entró a ser maestra ese mismo año y todavía lo sigue siendo. Forman dos filas, en una los chicos, y en otras las chicas, estando cara a cara. El número de parejas es indeterminado. Utilizan castañuelas y panderetas (con unas tiras enganchadas a ésta), ambas cosas las niñas, y los niños solo las castañuelas. Es un baile sencillo. Es una danza introductoria, pues se realiza por infantes que aun ni siquiera están en edad de comulgar, y muchos de los que actúan en otras danzas cuando tenían esa edad pasaron por ésta. Los dos más mayores son el "Rey y la Reina", representando el papel de pastor en el caso de él, y la Divina Pastora ella. Ésta lleva la figura de un cordero, que tiene la simbología de representar a Cristo.

Las chicas visten con una blusa blanca, faldas de diversos colores, delantal, chaleco, calzas y alpargatas de esparto, mientras que los chicos utilizan un pantalón negro que llega hasta las pantorrillas, blusa blanca, faja, calzas blancas y alpargatas de esparto. Ambos sexos llevan sombrero de paja, pero no lo tienen puesto sobre la cabeza, sino que al estar atado lo llevan echado hacia atrás en la espalda, a modo de capucha. También portan una especie de bolso. 
La música es realizada con dolçaina y tabalet. Pueden realizar hasta seis bailes, aunque en realidad existen siete, pero uno se realiza. Esto van numerados, y el 5, 6 y 7 se realizan frente a cerámicas con imagen de la virgen. No siempre se hacen todos.

Por otra parte, las otras dos, son danzas formadas por niñas adolescentes. La música de ambas se realiza con dolçaina y tabalet. En la primera de ellas, el baile gira alrededor de un palo que es sostenido por dos niñas, en el cual hay cintas atadas, y cada una de las doce adolescentes que actúa coge a una de éstas, y van atándolas o desatándolas según la dirección a la que se dirijan. Éste está coronado por una carxofa. Por tanto es una coreografía circular. Tiene una única composición musical y un solo baile, que puede ser simple o doble. En su origen fue conocida como el Baile de las Tejedoras.

En cuanto a su vestimenta, está formada por una blusa blanca y una falda, cada niña de un color, calzas blancas, una especie de delantal negro, chaleco sin pasado y alpargatas de careta. Llevan franjas horizontales de color negro en el cuerpo y la falda, y en la espalda unos bordados.

Fotografía 3. El Ball de la Carxofa actuando en la Plaça Major

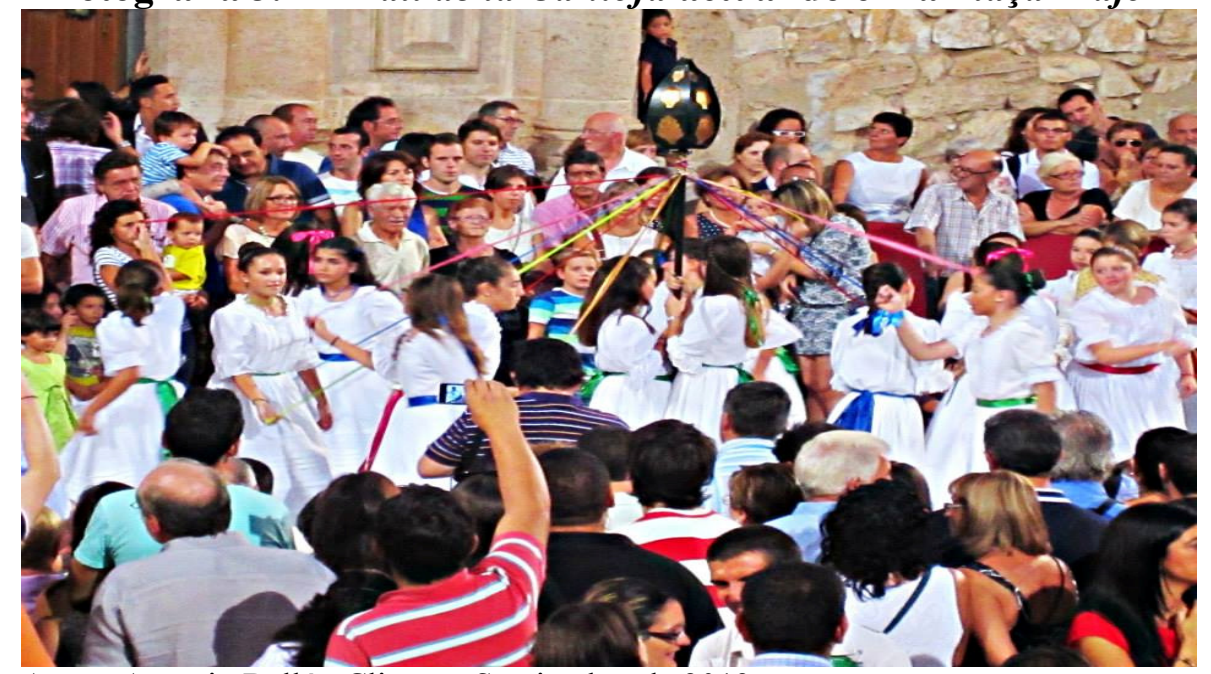

Autor: Antonio Bellón Climent. Septiembre de 2013.

Els Arquets procede de la anterior. Se dividieron en 1988, siendo ahora una danza independiente de la otra. Está formando por doce chicas, y cada una lleva un aro, realizado con papel, de colores diferentes, y la coreografía consiste en bailar a la vez que también van girando los aros al ritmo de la melodía. El vestido es de color blanco, guardando similitud al de la comunión. Representan la virginidad. Llevan cintas de colores en la coleta (las que llevan) a juego con la de la cintura.

\section{Les Llauradores}

Es un baile alóctono en esta celebración, que hasta su consolidación en la procesión actuaban en fiestas de calles, y fueron los últimos en incorporarse, realizando su primera aparición en 1906. Es el que menos carácter religioso presenta, o lo que es lo mismo, el más profano. No tiene elementos simbólicos en relación con la virgen. Desde su debut participaron dos años seguidos, luego desaparecieron, para volver a aparecer en 1934, y 
hasta 1940 no volvieron a salir, y a partir de esta fecha ya lo han hecho de forma continua.

Es uno de los bailes de la procesión en los que más se identifica el público debido a su vestimenta. Es la danza más elegante, y es la que durante el proceso de realización más extensión abarca. Es mixto, pues está formado por parejas, no hay un número fijo de éstas, sino que actúan según el número de ellas inscritas. Hay muchas. Se baila por turnos. No existe una uniformidad de edad. Existe una gran demanda por entrar a formar parte de este grupo, habiendo lista de espera.

En cuanto a la indumentaria, no existe un modelo único para la mujer. Llevan vestidos valencianos con elementos tradicionales entremezclados de los siglos XVIII y XIX, primando los del primer siglo. En la parte que comprende desde los hombros hasta la cintura llevan un jubón generalmente con manga de medio corte, pañuelo enrollado sobre éste y con numerosos bordados dorados generalmente, falda larga, calzas blancas. Destacan por su peinado, sus pendientes y por llevar numerosos adornos. Los hombres visten con traje torrentí. Este se compone de alpargatas de esparto con cordones negros que se atan sobre las calzas blancas, un calzón, que llega hasta un poco más abajo de la rodilla, faja, blusa blanca y sobre ésta chaleco. El calzón y el chaleco pueden ser de diferentes colores, pero sí que han de coincidir las dos prendas con el mismo color, y la faja de otro diferente a estos. Algunos llevan gorro.

Cada bailador lleva una castañuela, que ejecutan al ritmo del baile. Exige coordinación entre piernas y brazos, a la vez que con las castañuelas mientras se actúa. La principal característica es que es una de las dos danzas que no es interpretada por dolçaina y tabalet. La música es realizada a través de una banda de viento, destacando la tuba, el bombardino de pistones, el clarinete, la trompa, la trompeta y el trombón. Tiene seis bailes diferentes, y el mismo número de melodías, pero cada uno de éstos no es la coreografía fija de una de estas representaciones musicales, sino que se pueden utilizar para todas, y viceversa. Éstos son: València, Reies, Trensaor, Típics, Madrid y Botí. En cuanto a la música la más característica es el Bolero Mallorquí, con tres versiones, pero también están los boleros Pardines, Processó y del Centenari.

Tienen un estilo diferente al de los otros boleros, pues estos últimos tienen por lo general tres partes separadas por una especie descanso cada una, mientras que las Llauradores se caracterizan porque al tener una procesión detrás deben ser más breves, y por ello solo realiza una pausa, por tanto tiene dos partes. Un aspecto característico es la manera de acabar la representación, quedándose totalmente estáticos y mirando a un punto fijo durante un breve momento.

\section{Els Tornejants}

Es la danza más emblemática junto a la Muixeranga. Encontramos testimonios escritos en el año 1800, pero parece ser que tuvieron un origen anterior. Está formada por seis miembros, un paje y los botargues (que son los niños que llevan las varas). Representan a los caballeros encargados de proteger a la virgen, con una amplia carga simbólica en las coreografías que realizan, con un número fijo de personas para realizar cada una de ellas. 
Tiene un origen burgués. Esto además se demuestra en los vestidos, que son de mejores materiales que los de otras danzas, y en que salen en la parte religiosa de la procesión. Por tanto en el pasado fue considerado como el baile de una clase económica y social más alta, vinculado con la burguesía agraria.

$\mathrm{Su}$ vestimenta presenta carácter barroco, y se compone de un chaleco y falda blanca, recorridos por tiras horizontales doradas, calzas blancas, alpargatas que tienen una especie de cinta que hace la función de cordones que van subiendo por éstas. Llevan un pasador en la espalda ornamentado con símbolos florales dorados. La cabeza aparece cubierta con casco, con una máscara de alambre, terminando éste con una pronunciación vertical en la parte delantera, y culminación floral en forma de cruz roja sobre la base de la testa. Este vestido es parecido al que llevaban los caballeros en los torneos medievales.

Actúan al ritmo del timbal. Existen diferentes bailes, entre los que se pueden destacar "el Mago", "les Floretes" y "la Fuga". Las danzas las realizan con una vara, larga y fina, de unos 120 centímetros de longitud, y uno de los momentos de mayor suspense es cuando las lanzan al aire. Si en algún instante ésta se les cae, no se agachan a recogerla, sino que es el botarga el que se acerca para darle una nueva, pues este va provisto con una cesta con algunas de recambio. Tienen un gran desgaste físico, pues no llevan sustitutos, y como se dice popularmente, "los que empiezan la procesión son los mismos que la acaban".

El paje es el heraldo, con la espada en la mano y el escudo con forma de corazón con la imagen pictórica de la virgen en la otra, realiza el baile "el Paje", por delante de la comitiva, extendiendo el brazo derecho con la espada levantando de forma alterna una pierna de forma horizontal a cada golpe del timbal, al ritmo que le va marcando éste.

Su representación más emblemática es "la Fuga", que para su realización necesitan a los seis miembros. Es una actuación difícil de hacer, porque en realidad alterna diversos bailes, aparte de que es la más larga. En ella se representa una lucha. Comienzan con el Paseo, luego viene el Torneo y por último las Cabriolas, destacando el final, con unos segundos apoteósicos con el sonido del timbal, y acabando con una genuflexión los seis. "Les Floretes", que es el que se realiza frente al Guió. Cuando éste sale de la iglesia o la capilla, actúan frente a él, para terminar con una genuflexión. De uno en uno van realizando esta representación. Es como una especie de presentación. Durante su recorrido, en aquéllos lugares donde hay una cerámica mariana hacen lo mismo. Uno de sus momentos cumbre, es en la "entrada de la Mare de Déu", donde situados detrás de ésta, y mirándola de cara, le apuntan con las varas, y yendo hacia adelante y hacia atrás compenetrándose con los movimientos del anda. Esto simboliza que son sus guardianes y hasta que esta no está dentro definitivamente la custodian, pues son sus guerreros.

\section{El Tabalet y la Dolçaina}

Esta fiesta no sólo es un patrimonio de carácter folklórico. También es un verdadero tesoro musical, donde destacan dos instrumentos: el tabal y la dolçaina ${ }^{3}$. Ambos son vitales. Existe la primera documentación del uso de esta última en 1733.

El tabalet es un instrumento musical de percusión con forma cilíndrica y que está recubierto de piel, y que para producir el sonido se ha de golpear con unos palos conocidos como baquetas. Mientras la segunda, es un instrumento de viento, y que se 
sopla a través de una boquilla estrecha, y que en su cuerpo externo, que es una madera cilíndrica con agujeros (parecidos a los de una flauta), se puedan realizar con los dedos del músico las diferentes notas, para que en su cuerpo interior se transforme el sonido.

Las composiciones musicales se habían transmitido desde su origen por transmisión oral. Durante las décadas de decadencia de la fiesta a mediados de siglo XX, no hubo ningún dulzainero local. Esto provocó que en 1971 se planteara la posibilidad de pasar a realizar la composición sonora con clarinete. Algunas personas lo impidieron. Por tanto no solo se vivió una "crisis de muixeranguers", sino también de "dolçainers", pues estos prácticamente habían desaparecido. Fruto de este resurgir que se vivió con la "recuperación de la Muixeranga", nació en 1974 la Escola de Tabalet i Dolçaina, con el objetivo de que nunca volviese a haber escasez de músicos locales. Es la más antigua de la Comunidad Valenciana.

Son actores principales de las procesiones, pues realizan la composición musical de cinco danzas: la Muixeranga, els Bastonets, les Pastoretes, els Arquets y la Carxofa. Cada una de éstas tiene sus diferentes melodías, interpretadas a través estos instrumentos. De ahí la importancia que ha venido adquiriendo esta escuela en las últimas décadas. Tiene más de doscientos cincuenta miembros. Debido al prestigio de la fiesta y de la música que se realiza con estos instrumentos durante esta celebración, son muchos los músicos forasteros que desean venir a tocar en ésta. En las procesiones actúan alrededor de cuatrocientos dulzaineros, y una característica es que no cobran por salir en ellas, sino que lo hacen por el amor a esta tradición. También son un elemento clave en el acto de "la plegà", donde tampoco se les pagan, sino al contrario, acompañan amenizando con sus melodías a los festeros para recoger dinero por el pueblo.

La melodía La Muixeranga es la que acompaña a las representaciones de las torres humanas de la danza homónima. Es la más conocida y representativa de toda la fiesta y del municipio de Algemesí, y ha traspasado sus fronteras. Se ha convertido en un símbolo del pueblo valenciano. Se caracteriza por no tener letra. Los sectores culturales del País Valencià la reclaman como himno regional. El partido político de Esquerra Unida (EU), pretende que ésta acompañe al Himno de la Exposición (el oficial de la Comunidad Valenciana) en los actos representativos valencianos. Para ello presentaron una proposición no de ley. Creo que esta melodía tan bella y emblemática nunca debería desgajarse del elemento al que siempre ha ido unido (bajo ningún pretexto, $\mathrm{y}$ menos político), y del que recibe su nombre. Pues si se llegase a realizar esta medida, se crearían polémicas, pues no sería aceptada por todo el mundo, y La Muixeranga debe servir de elemento integrador de la cultura valenciana, y no para dividir. Se debe evitar su politización.

En una pena que pese a su belleza musical, estos instrumentos hayan tenido muy poco reconocimiento. Aunque cabe señalar que por lo menos se han visto recompensados por tener ya un Plan de Estudios. Como conclusión, señalar que a día de hoy, el mejor concierto de dolçaina y tabalet es el que se realiza en las calles del municipio de Algemesí en los días 7 y 8 de septiembre.

${ }^{3}$ Para escuchar todas las melodías de la fiesta consultar en el Museu Valencià de la Festa, en Festa, La Música, disponible en http://www.museuvalenciadelafesta.com/. 


\section{Elementos de carácter religioso de la procesión}

En este apartado se verán todos los aspectos cristianos de la festividad, los que aparecen en alguno de los tres itinerarios, o bien las omnipresentes campanas.

\section{Parte religiosa de la procesión}

Antes de que comiencen a actuar las danzas, como preludio, aparecen los Misteris y Martiris, que están formados por niños que van representando entre el público asistente obras teatrales, de muy breve duración, y que tienen su origen en el Corpus Christi. Aparecen documentados por primera vez en 1883. Según el orden de representación tenemos:

-El Misteri de la temptació. Narra la historia de Adán y Eva, y como esta es tentada por el demonio y le ofrece la manzana a él.

-El Misteri d'Abraham e Isaac. Representan la escena en que Dios le dice a Abraham que sacrifique en su honor a su hijo, y este le obedece, y entonces le premia por su obediencia con salvar la vida de Isaac.

-El Martiri de Santa Bàrbara. En éste se escenifica el martirio de ésta cuando es encerrada en la torre por su padre para luchar contra su conversión al cristianismo.

-El Martiri de Sant Bernat i les seues germanes. Trata de como Bernardo y sus dos hermanas, mantienen su creencia en el cristianismo aun en presencia del Rey moro Almanzor.

-El Misteri de la Mare de Déu Salut. Narra la leyenda de la Troballa y del Retorn a la morera tras ser llevada a Alcira.

-El Misteri dels Capellanets. En él se representa el momento en el que se reúnen los tres sacerdotes para ponerle nombre a la virgen mediante sorteo, y las tres veces salió "de la Salut".

La Cruz, que sale tras las Llauradores, marca el inicio de la verdadera procesión, o la parte religiosa de ésta. Es de estilo barroco y está hecha de plata. Su autor fue Antoni Reinot en 1739. Va acompaña del sonido de la dolçaina. Uno de los momentos más bonitos y desconocidos por parte del público es la entrada de ésta en la Basílica, pues todos los dolçainers de las diferentes danzas conforme van llegando y terminando, esperan la llegada de ésta en la puerta. Y que aunque tenga una connotación religiosa, pues es la entrada a la iglesia de un elemento cristiano, el hecho de escuchar la música, pues actúan todos los músicos, hace que sea uno de los instantes más emocionantes.

Luego aparece el Guió, que es una especie de cuadro de plata repujada, y que contiene un lienzo con imagen pictórica de la Mare de Déu de la Salut dentro de la morera, siendo adorada por ángeles. Se puede apreciar claramente su estilo barroco debido a que el marco es muy exagerado en sus formas, pues son curvas y muy grotescas. No existe documentación de quién fue su autor. Está rematado el marco por la imagen de San Jordi matando a un dragón.

A continuación, solo en la Processó de Volta General, a diferencia de la otras dos, se incorporan los personajes bíblicos. Son elementos con origen en el Corpus Christi de 
Valencia. Su primera documentación la tenemos en 1834. También han sufrido épocas de crisis, con la desaparición de algunos de ellos, y en 1972 se creó la Asociación de Trajes Bíblicos, con el objetivo de recuperar estas figuras y de ser autodependientes en cuanto al tema de los vestidos. Se estructuran entre los del Antiguo Testamento y los del Nuevo Testamento. De los primeros tenemos a los Patriarcas, como Noé, que se identifica por llevar un bastón y una paloma, Abraham, que lleva un cuchillo, Isaac, con una haz de leña, Jacob, y "Els Blancs", que son los doce hijos de éste y que son los padres de las doce tribus de las que según la Biblia desciende la humanidad. Éstos últimos desaparecieron hace décadas y se han recuperado en el 2007. También aparecen los caudillos de Israel, Moisés que se distingue por llevar las tablas, y Josué, con la espada para parar el sol. Cabe destacar uno de los elementos más simbólicos de esta parte de la procesión, que es la parra de vid, y que representa la tierra prometida. Luego aparecen personajes bíblicos menos distinguidos

Del Nuevo Testamento tenemos los Doce Apóstoles, que aparecen en 1836, y los Cuatro Evangelistas, que se tiene documentación de ellos desde 1855. Por último los Cirialots, que son los veinticuatro ancianos del Apocalipsis. Aparecieron por primera vez en 1842, y son una figura que había desaparecido durante las décadas que la fiesta vivió la crisis, y que se recuperaron en el año 2008.

Bien acompañando o bien transportando al anda de la Mare de Déu de la Salut, aparecen los Volants. La función de éstos es la de ser sus guardianes. Su vestimenta se compone por calzas blancas, calzones rojos con franjas blancas bordadas, jubón blanco y capa roja con franjas blancas. No se sabe el porqué de su nombre, pero entre las diversas teorías parece ser que la más acertada es la que apunta que la palabra deriva de llevar al vuelo el anda, pero solo es una suposición. Aparecieron por primera vez en 1852. Eran un grupo formado por las clases altas en sus inicios, pero desaparecieron a mitad de siglo XX. Se recuperaron en 1985.

\section{Las Campanas}

Uno de los principales elementos de esta festividad es el sonido de las campanas, aunque en las últimas décadas han surgido controversias, debido a que algunos vecinos se han quejado de éstas, y de tener que escuchar su sonido a altas horas de la noche en los días que preceden a las procesiones. El campanario alberga cinco campanas, cada una con una función y nombre propio: San Onofre, San Vicente, Cristo del Agonía, Mare de Déu de la Salut y San Jaime. En esta localidad «s'han mantingut dos tocs tradicionals, gràcies a les mans poderoses i savies dels campaners, els quals es tornen a tocar a braç» (Olivares, 2003, p.24). Estos toques son el Retorn y la Xirivía. Éstos solo se realizan una vez al año. Su significado es algo que la mayoría de la gente desconoce, pues estas tienen la capacidad de narrar, pero es un lenguaje que hoy día muy pocas personas entienden, pues con el paso del tiempo se ha ido perdiendo.

Es de destacar el simbolismo del Vol del Retorn, que se realiza como su nombre indica, la noche del 6 de septiembre a las 24:00 horas. Narran la ida y vuelta de la Virgen de la Salud a Alcira. Se divide en dos partes. En la primera representa su ida a esta ciudad vecina, con una duración de unos nueve minutos, en los que van sonando cada una de las cinco campanas de forma individual durante un minutos, siguiendo el siguiente orden: San Onofre, San Vicente, Cristo del Agonía, Mare de Déu de la Salut, San Jaime, Mare de Déu de la Salut, Cristo del Agonía, San Vicente y San Onofre. Cuando 
está terminando esta primera parte ( $\sin$ que lo haya hecho), se inicia la segunda que consiste en el Retorn, anunciado por el volteo de todas ellas. Primero actúa la campana más pequeña, San Onofre, uniéndose luego San Vicente, que es la segunda con menos tamaño, más tarde Cristo del Agonía, y así sucesivamente hasta que tenemos a las cinco volteando a la vez. Es decir se han ido uniendo de menor a mayor tamaño. Luego se produce el proceso inverso, van disminuyendo de más pequeña a más grande, para ser la última en quedar volteando San Jaime. Esta segunda parte dura tres minutos. Se realiza durante tres ocasiones. Antaño el volteo se realizaba durante toda la noche, pero las quejas de los vecinos hicieron que se tuviera que reducir, para sonar el proceso cada hora en punto, desde su inicio hasta las 6:00.

El repique Xirivía tiene su origen en la Seu de Valencia, y es una adaptación de "Bendición del Miguelete", pero aquí tiene su singularidad respecto al anterior, y se caracteriza porque todas las campanas repican de forma aislada. Este toque dura aproximadamente media hora. La tarde del 7 de septiembre, cuando a las 19:00 la imagen de la Mare de Déu de la Salut es llevada desde el altar de la capilla de la Comunión a la Mayor de la nave principal, tras cantar el Virolai y realizar las Vísperas, se procede a este toque. Su parada marca el inicio de la procesión.

\section{LA ORGANIZACIÓN DE LA FIESTA}

En este epígrafe se hablará de aquellos organismos locales encargados de la organización de la Fiesta. En un primer apartado se explica el recorrido de las tres procesiones. Luego se analizarán los métodos que se utilizan para la promoción, y algunas medidas que se han tomado para el desarrollo y la mejora de la festividad. Acto seguido se verá cual es el papel de los festeros en la organización de la celebración, y qué acciones realizan para recaudar dinero para poder costear los gastos que ésta genera. Y por último se detallará un actor de vital para la difusión de ésta en los últimos años, el Museu Valencia de la Festa.

En la actualidad Patronat de la Festa es el responsable de la Fiesta. Este nace en 1997. Según el artículo 3.2. del Decreto 117/2010, por el cual fue declarada como Bien de Interés Cultural, «la gestión de la Festa a la Mare de Déu de la Salut, al margen de los actos litúrgicos que corresponden a la Iglesia, es competencia del Patronato [...], quienes decidirán sobre los aspectos materiales e inmateriales, así como el desarrollo de los actos de la festividad anual».

A diferencia de otras tradiciones valencianas con trayectoria centenaria, no ha sido necesario recurrir a los tribunales para la entrada de la mujer a participar en algunos elementos de la celebración, a los que hasta hace no mucho tiempo estaba vetada. Por ejemplo cuando en 1997 la Nova Muixeranga (que se había creado con el fin de que la mujer pudiese participar en esta manifestación) le propuso al Patronat de entrar a formar parte de la procesión, éste acepto, y al año siguiente pudieron participar por primera vez en ésta.

El Ayuntamiento en la actualidad es el que sufraga los gastos de difusión. La fiesta viene precedida de una serie de preparativos. Éstos comienzan en mayo, cuando los órganos municipales preparan las invitaciones para los representantes de las diferentes instituciones, principalmente para la procesión matinal, y también se realizan las bases para el concurso del "Cartell de la Mare de Déu", que se realiza todos los años desde 
1979. En junio se comienza a preparar los programas de las festividades, y las danzas se reúnen con el Ayuntamiento junto al Patronat de la Festa. También se encarga de las medidas de protección civil, ejecutadas con la Policía Local, Cruz Roja y Protección Civil, ésta última desde 2012, apoyados por la Policía Nacional.

También hay que preparar el alquiler de las infraestructuras que serán necesarias. Tras la declaración de la UNESCO se han ampliado para ganar capacidad de carga las gradas que se montan en la Plaça Major para poder ver los actos que se realizan en ésta. Es de alabar la habilitación de un entablado en ésta para que las personas con discapacidad física puedan ver la actuación de las danzas y la entrada de la Mare de Déu. Por otra parte, desde 2012, en un tramo de la calle Muntanya se han puesto a disposición 500 sillas para que aquellos visitantes que paguen 3 euros puedan ver el final de la Processó de Volta General cómodamente y en primera fila.

\section{EI recorrido de las procesiones}

En este apartado se describirá un elemento importante, es decir el itinerario de cada una de las tres procesiones. Tenemos constancia documentada de esta celebración en 1610. Pero entonces sólo recorría la calle Berca. En 1680 a tener un carácter local. La fiesta se estructura en tres procesiones desde 1880. Cada una de éstas tiene recorridos, características y simbolismos diferentes. Se detallarán algunas singularidades de cada una, y también aquellos elementos patrimoniales relacionados con la celebración que merezcan la atención. Tras el análisis de cada una de ellas, se podrá observar a través de un mapa los recorridos. Un aspecto que llama muchísimo la atención que las danzas actúan de una manera muy anárquica, aunque sí que existen algunos puntos fijos en los que se realiza algún baile específico.

Cabe señalar que el momento más emblemático, bello y emocionante de toda la celebración, es la entrada en la basílica de la Mare de Déu. Tres veces hace el amago de entrar, y tantas sale unos pasos hacia fuera. Esto hace referencia a las tres veces que salió del pueblo para ser llevada a Alcira, y las mismas ocasiones que según cuenta la leyenda volvió a ser encontrada en la morera, ya en la tercera para quedarse definitivamente.

Pero antes de empezar a explicar los tres recorridos, conviene hablar de las dos principales edificaciones religiosas que se encuentran dentro de este perímetro, pues aparte de ser hitos locales tienen un importante valor patrimonial para las personas que visitan este municipio con fines turísticos o culturales, que son punto de origen y destino de las procesiones. Estos son la Basílica Menor de San Jaime y la Capella de la Troballa.

En uno de los lados de la Plaça Major, se encuentra la Iglesia. En 1980 fue declarada Bien de Interés Cultural y en 1986 se le concedió la categoría de Basílica Menor. Arquitectónicamente cabe destacar su portalada, de estilo renacentista y que fue realizada en el periodo comprendido entre 1552 y 1574 . Uno de los momentos más bonitos de las procesiones se produce ya dentro de la iglesia, pues las danzas conforme llegan a ésta, entran y actúan dentro. 
La Capella de la Troballa es una edificación simbólica para este municipio. Fue construida en 1688, en el espacio donde se encontraba la morera. Pero durante la Guerra Civil fue destruida, y en 1947 se levantó la actual, de estilo neogótico.

El día 7 de septiembre, a las 22:00 se inicia la primera procesión, que es conocida como Processó de les Promeses, porque «tras el Guión se colocan las dos hileras de fieles con cirios» (Atienza, 1991, p.4), pidiendo la realización de un favor a la virgen o en agradecimiento de haberse cumplido éste. El recorrido que realiza tiene como origen la Basílica de San Jaime, para tras salir por la Plaça Major, recorrer calles Molí y de la Capella, y hacer su entrada en la Calella de la Troballa, por su puerta lateral. Se inicia con la realización del "Ball" por la "Blava", y tras esto hacer "l'Alta" frente a la Casa Consistorial. Luego van saliendo todas las danzas en su orden habitual, realizando su primera actuación frente a ésta, $\mathrm{y}$, para llegar más tarde a un momento esperado durante todo el año, la salida de la Virgen, que se produce alrededor de las 24:00 horas.

La mañana siguiente comienza con la Processoneta del Matí, a las 10:00 horas, teniendo su punto de origen en el mismo lugar donde termino la noche anterior, con la Plaça del Pouet llena de gente. Recorre la calle Berca, en la que todos los balcones se encuentran llenos de gente y engalanados con manteletes, con las dos aceras llenas de sillas y todas las puertas de las casas abiertas. Es de las tres la que más visitantes atrae, la que se ha potenciado más, en parte por la falta de alojamientos en el municipio, aspecto que se analizará en el último epígrafe. Un elemento que va a llamar mucho la atención durante todo el acto, es el elevado número de cámaras y fotógrafos.

Durante su recorrido se pueden destacar diferentes cosas que solo se realizan en esta procesión. Por ejemplo, se puede ver un elemento que hace poco se ha recuperado, y que solo participa en ésta, que son las figuras de los gigantes de Jaume $1^{e r}$ y $\mathrm{Na}$ Violant, y que son llevados por el Berca Group Danses d'Algemesí. Estos desaparecieron en el año 1968, siendo recuperados en 2007. Cuando las danzas pasan por delante del Pouet, donde según cuenta la tradición "se enterró la morera y brotó una fuente", hacen un baile fijo que sólo realizan frente a las cerámicas marianas. Todos los bailes acaban dentro de la Iglesia. Es de largo la más visitada, y destaca por su emocionante final, con todas las danzas actuando a la vez en la "entrada de la Mare de Déu" en la basílica, con una escalofriante mezcla de sonidos musicales, con cada una de las melodías de éstas, el volteo de campanas, mientras la imagen mirando a la gente, realiza la acción simbólica de entrar y salir, para introducirse definitivamente a la tercera vez, con la Plaça Major y el inicio de las calles que desembocan a ésta abarrotadas de público. Y si hace un día soleado, tiene un gran mérito estar presente, pues hay que tener en cuenta la fecha en la que estamos y la concentración de personas, cosa que hace que las temperaturas y la sensación térmica puedan ser muy elevadas, aspecto que se visualiza en el hecho de que mucha gente utiliza abanicos.

Por la tarde, a las 19:00 horas, arranca la última, y se caracteriza porque es la que tiene un recorrido más largo, pues recorre prácticamente el perímetro del centro histórico, lo que «els algemesinencs coneixem com "carrers de volta", un marcat recorregut perimetral per la vila del segle XVIII, on per avui encara discorren els actes festius de major importancia, una mena de vía honorum, per on transcorre clar està la Festa Major d'Algemesí, la processó de volta general a la Mare de Déu de la Salut. Espais d'història $i$ tradició, indrets, casalicis i carrers amb un plus de consideració en la idiosincràsia dels habitadors de la ciutat» (Domingo, 2004, p.71). El recorrido es el inverso al de todas las procesiones que se realizan a lo largo del año, e incluso a los de 
las otras dos de esta celebración, cosa que tiene un carácter simbólico, pues la pone por encima de todas las demás. Tiene como comienzo y final la Basílica de San Jaime. Tras su inicio en la Plaça Major, recorre las siguientes calles: València, Plaça dels Àngels, dels Mont, Albalat, Santa Bárbara, dels Verdeguers, Plaçeta del Carbó, Berca, Capella, Moli, Nou del Convent, dels Fusters y Muntanya, para finalizar en el mismo lugar que empezó.

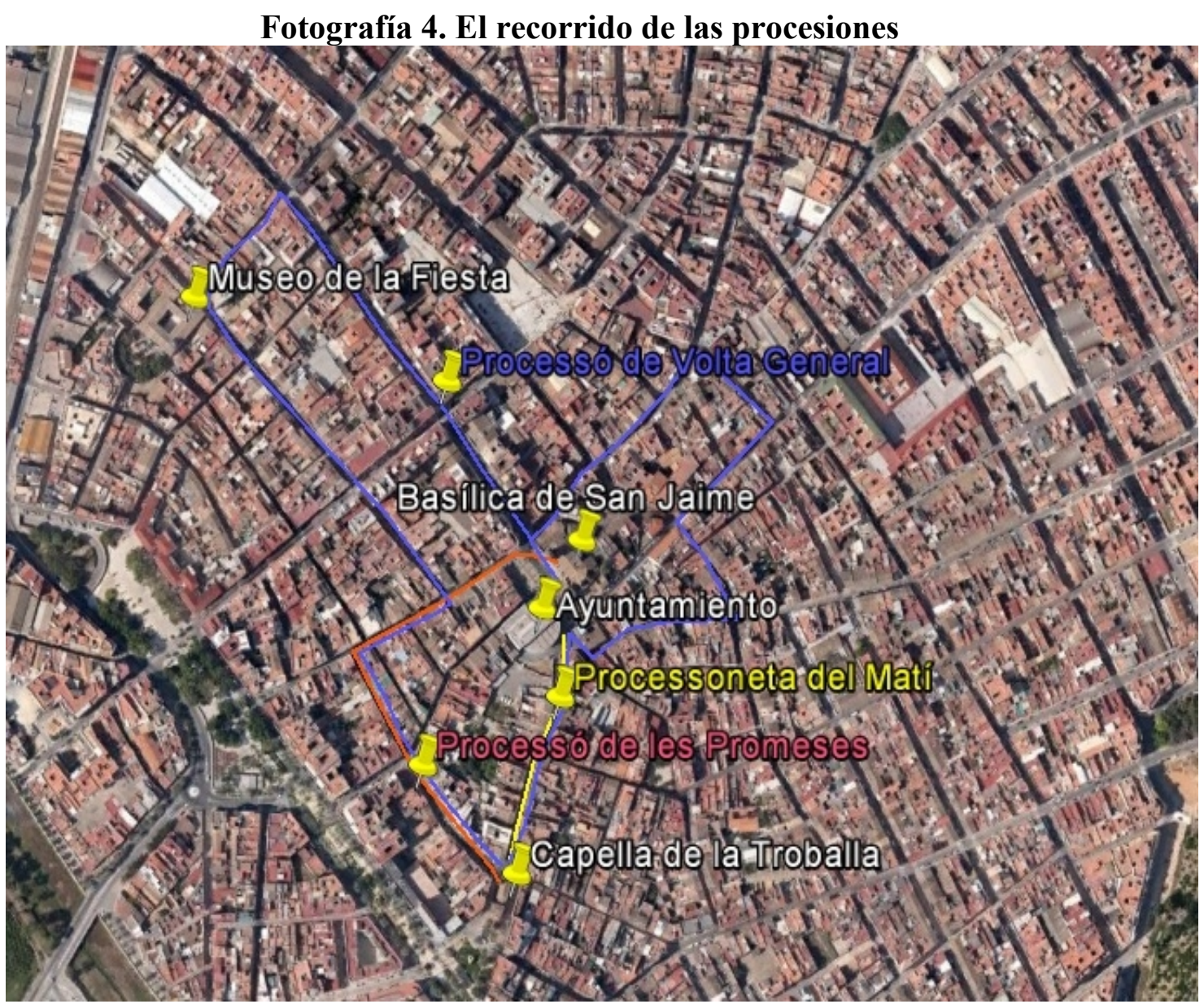

Fuente: Elaboración propia a través de Google Earth.

En estos carrers de volta encontramos diversas cerámicas en las que se representa alguna imagen mariana o de algún santo ${ }^{4}$. Estas obras son conocidas como retablos. Por estas calles se encuentran diversos de éstos en los que aparece representada la Virgen de la Salud. Solo se hará referencia a éstos. Son elementos muy importantes para la simbología de la fiesta, porque delante de ellos las danzas suelen realizar actuaciones específicas. Para empezar se puede hablar del taulell del n ${ }^{0} 38$ de la calle València, que se encuentra sobre el balcón del primer piso. Es de finales de siglo XVIII. Otro lo encontramos en el $n^{\circ} 6$ de la calle Santa Bárbara. Pero de entre estos retablos, el más entrañable y simbólico, debido a su ubicación, es el del no 38 de la calle Berca, es decir la casa del Pouet, estando situado encima de la fuente. Es de 1940, de estilo clasicista.

\footnotetext{
${ }^{4}$ Para obtener mayor información sobre esta temática en el municipio de Algemesí, consultar Olivares, E. Cerámica devocional urbana d'Algemesí. Algemesí: Ajuntament d'Algemesí, 2003.
} 


\section{La promoción}

Se ha potenciado la imagen de esta celebración, en gran parte a través de su divulgación con el uso de las tecnologías de la información y la comunicación. Para muchas personas que no sean de este municipio, la imagen a través de internet de videos, por ejemplo de la entrada de la Mare de Déu o de alguna torre de la Muixeranga, puede hacerle desear descubrir esa sensación en persona, y crearle el deseo de desplazarse para verla in situ. Aunque generalmente la gente que viene aquí (por lo menos hasta hace poco tiempo) tiene un conocimiento previo. Pero debido a esa divulgación (junto a la declaración de la UNESCO) se está cambiando esta tendencia.

Ha aumentado la promoción, sobre todo tras el tras recibir la calificación como Patrimonio Inmaterial de la Humanidad, donde destaca el ofrecimiento del año pasado de RENFE para poner carteles publicitarios sin costo alguno. Los días anteriores a las celebraciones, mediante estos, en los trenes de cercanías que cubren las líneas ValenciaJátiva y Valencia-Gandía se anunciaba esta fiesta, y también aparecía ésta en la pantalla de la maquina en la que se sacan los billetes. Además a cada hora a través de mensajes de megafonía se animaba a los usuarios del servicio ferroviario a que acudiesen a Algemesí a presenciar las procesiones. Existe un interés por parte de la empresa de ferrocarriles de promocionar esta festividad, pues el tren es uno de los medios de transporte más adecuados para acudir a esta localidad para presenciarla, debido a la cercanía de la estación con el centro histórico, y con esta publicidad se puede conseguir aumentar el número de visitantes que decidan utilizar este medio de transporte para acercarse a Algemesí.

Pero el mayor elemento de difusión, fue con las retransmisiones por primera vez de las procesiones en directo por la televisión autonómica valenciana de Canal 9 (ya desaparecida). Ésta prácticamente había ignorado a esta celebración, pues siempre que llegaba la fecha del 8 de septiembre, la sacaba unos segundos en los telediarios, dándole casi la misma importancia que a otras festividades realizadas el mismo día pero sin apenas trayectoria historia, y siempre al día siguiente de haberse realizado. En 2013 se decidió a retransmitir las procesiones porque ya no tuvo más remedio debido a que ya resultaba escandaloso que no le prestase atención a una celebración declarada Patrimonio Inmaterial de la Humanidad por la UNESCO. Por tanto se puede decir que esta tradición hasta que no ha sido reconocida por diferentes organismos e instituciones, prácticamente no ha tenido el respaldo promocional de los medios de comunicación autonómicos. Ahora, pese a que esta ya no existe, alguna televisión tendría que apostar por la retransmisión de esta festividad histórica, al menos de alguna de sus procesiones, siendo la Processoneta del Matí la más asumible por su horario y por su corta extensión.

Cabe señalar que cuando la Fiesta aún no había recibido los reconocimientos, su promoción a partir de la década de los noventa venía a través de asistir a ferias, en las cuáles había que explicar las razones del porqué de su asistencia, casi todas éstas de ámbito regional. A ellas era habitual llevarse algún elemento de la procesión para llamar la atención, y por ejemplo cuando veían actuar a la Muixeranga la gente preguntaba que "¿eso no es un castell catalán?”. Se comenzaron a hacer panfletos promocionales para que la gente que acudiera a esas citas se los llevara a casa. Poco a poco fue conociéndose la Fiesta en tierras valencianas. Esto es en parte es culpa de los medios de comunicación valencianos como se ha señalado anteriormente, pues hasta a haber recibido las diferentes menciones no han promocionado esta festividad. Pero en este 
aspecto se produjo un cambio en los últimos años, ya incluso antes de recibir las diferentes distinciones, debido a que las instituciones se dieron cuenta de lo rentable que era llevarla a diferentes ferias, y los organismos autonómicos comenzaron a tenerla muy en cuenta, comenzando a ir a FITUR, donde expone dentro del stand de la Comunidad Valenciana y no por cuenta propia. Por tanto se observa un interés económico por parte de las instituciones valencianas, y no por su valor patrimonial.

En la actualidad llama la atención que pese al gran alcance que ha tenido en los últimos años, con todos los visitantes de sitios lejanos que se acercan y todas las distinciones que ha recibido, pese a ello hay mucha gente en nuestro país que todavía no conoce esta fiesta, ni su gran valor inmaterial. Lo mismo ocurre con la Muixeranga, pues fuera de la provincia de Valencia, mucha gente no sabe qué es, ni la conocen, y si se pregunta o se le habla a personas sobre ésta, explicando que es una manifestación cultural que hace torres humanas (entre sus muchas composiciones), posiblemente su respuesta será que conocen los "castellers catalanes pero eso no".

\section{Los festeros}

En cuanto a la organización de la Fiesta, los festeros son los encargados de coordinarla y moverse para recaudar el dinero, pues este sale de donaciones de la población. Ésta se divide en cuatro barrios históricos, que son los que había a principios de siglo XIX y los que comprenden el perímetro de la Processó de Volta General, de los que cada año le corresponde la organización a uno de ellos, de forma sucesiva, pues van rotando. Éstos son: Capella, Muntanya, Santa Bárbara y València. En un primer momento, en 1747, se dividió la celebración en ocho, pero en 1835 se pasó a los cuatro actuales, aunque por entonces al de la Capella se le denominaba Molí. Cada uno se encarga de forma alternativa de organizarla cada año.

Funcionan de forma autónoma respecto de las instituciones municipales y eclesiásticas. Cada barrio tiene una directiva, con Presidente, Secretario y Tesorero, y numerosos Vocales. Toda persona puede ser festera. El único requisito para ello es dedicación e interés por la tradición. Se consigue financiación de diferentes formas. La principal de ellas es mediante lotería.

Para sufragar los gastos que se generan, a los festeros que les corresponde organizar la festividad en un determinado año, suelen realizar "detalles" que venden para poder contribuir económicamente al mantenimiento de todo lo necesario para que todo esté preparado. Por ejemplo los organizadores del Barrio de Valencia en el 2013 realizaron cintas que representan las medidas de la Mare de Déu de la Salut. Pues se necesita dinero para pagar gastos como los cirios, los fuegos artificiales, etc.

También se consigue dinero mediante donaciones, realizadas en el acto de la plegà, que lo realizan los festeros del barrio al que ese año le corresponde la organización. Recorren las calles del casco urbano acompañados de la música de la dolçaina, donde piden dinero a vecinos y en negocios. También durante el recorrido de las procesiones van con bandejas recogiendo monedas que dona del público. 


\section{LA EXPORTACIÓN DE LA FIESTA}

Es mayormente en el siglo XXI cuando ya de forma brusca se han superado las fronteras locales, pero principalmente convirtiéndose la Muixeranga y su melodía en un símbolo representativo de esta fiesta. Es frecuente que las danzas sean invitadas para actuar en otras localidades. También se realizan exposiciones en diferentes ciudades. Todo esto ha hecho que ya no sea una celebración de dos días, sino que esté presente durante todo el año, gracias al número de actos a la que es invitada, y por la labor de divulgación del Museu de la Festa

Uno de los actos más representativos en los que han estado presentes elementos de esta tradición, fue en la conmemoración del cuarto aniversario de la designación como Patrimonio Inmaterial de la Humanidad del Tribunal de las Aguas de Valencia, celebrado el 26 de septiembre de 2013 en uno de las sesiones en las que se reúne esta institución todos los jueves, a las 12:00 horas en la puerta de los Apóstoles de la Catedral de Valencia. Estuvieron allí los tres patrimonios reconocidos por la UNESCO de la Comunidad Valenciana: el Tribunal de las Aguas, el Misteri d'Elx y les Festes de la Mare de Déu de la Salut, representadas por la Blava, Verda, Bastonets y Tornejants.

\section{EI Museu Valencià de la Festa}

Se encuentra ubicado en el Convento de San Vicente Ferrer, que está en la calle Nou del Convent. A principios de los noventa se pensó en musealizar la celebración. Se empezó con la creación de una Escuela Taller con el objetivo de restaurar este edificio. Una vez se consiguió esto, comenzó la potenciación de un recurso endógeno, la festividad de la Mare de Déu de la Salut, con la apertura del museo, y para paliar que Algemesí no es una ciudad turística se realizaron una serie de exposiciones para servir como punto de atracción. También se vio conveniente aprovechar una serie de elementos históricoartísticos, como la Basílica de San Jaime o los edificios modernistas, con la creación de rutas para las visitas organizadas. Gracias a esto hoy se puede hablar de que existe un turismo cultural en esta localidad, pues es frecuente la llegada de visitantes esta institución y también se realizan visitan organizadas y guiadas, en las que aparte de visitar el museo se puede realizar la Ruta Modernista y la Ruta de la Llacuna del Samaruc. Cabe destacar que los días de las celebraciones, no se realizan visitas con guía por las procesiones, pues las características urbanas de los recorridos de éstas, hacen que esto sea inviable, porque las calles son muy estrechas y existe mucha concentración de personas, y cada uno se coloca dónde puede y es imposible funcionar en grupo ${ }^{5}$.

La entrada es gratuita. Junto a la puerta de acceso, a mano derecha se encuentra la Tourist Info. En su interior hay tres exposiciones permanentes, pero en esta investigación solo interesa la de La Festa de la Mare de Déu de la Salut, que se encuentra en el segundo piso ${ }^{6}$. Colgados en la pared aparecen los carteles de las fiestas de cada año. Hay una pantalla gigante que ofrece de forma continuada vídeos sobre las procesiones. También se encuentran expuestas todas las danzas. Cada una de ellas sobre una base de madera tiene un maniquí vestido con la vestimenta del baile correspondiente, junto a paneles explicativos de su historia, música e indumentaria.

\footnotetext{
${ }^{5}$ Entrevista a Julio Blasco, director del Museu Valencià de la Festa.

${ }^{6}$ Para obtener más información visual sobre los elementos de la fiesta, acudir a la página web del Museu Valencià de la Festa, disponible en http://www.museuvalenciadelafesta.com/.
} 
En el año 1994, una falla local, en su monumento infantil realizó una versión en cartón y madera de esta celebración. Ésta fue indultada. Se encuentra en el museo. Este monumento que ha pervivido como patrimonio cultural, ha sido expuesto en diferentes exposiciones temporales, como la de Milán en 2003.

Fotografía 5. Exposición permanente de la Festa en el museo

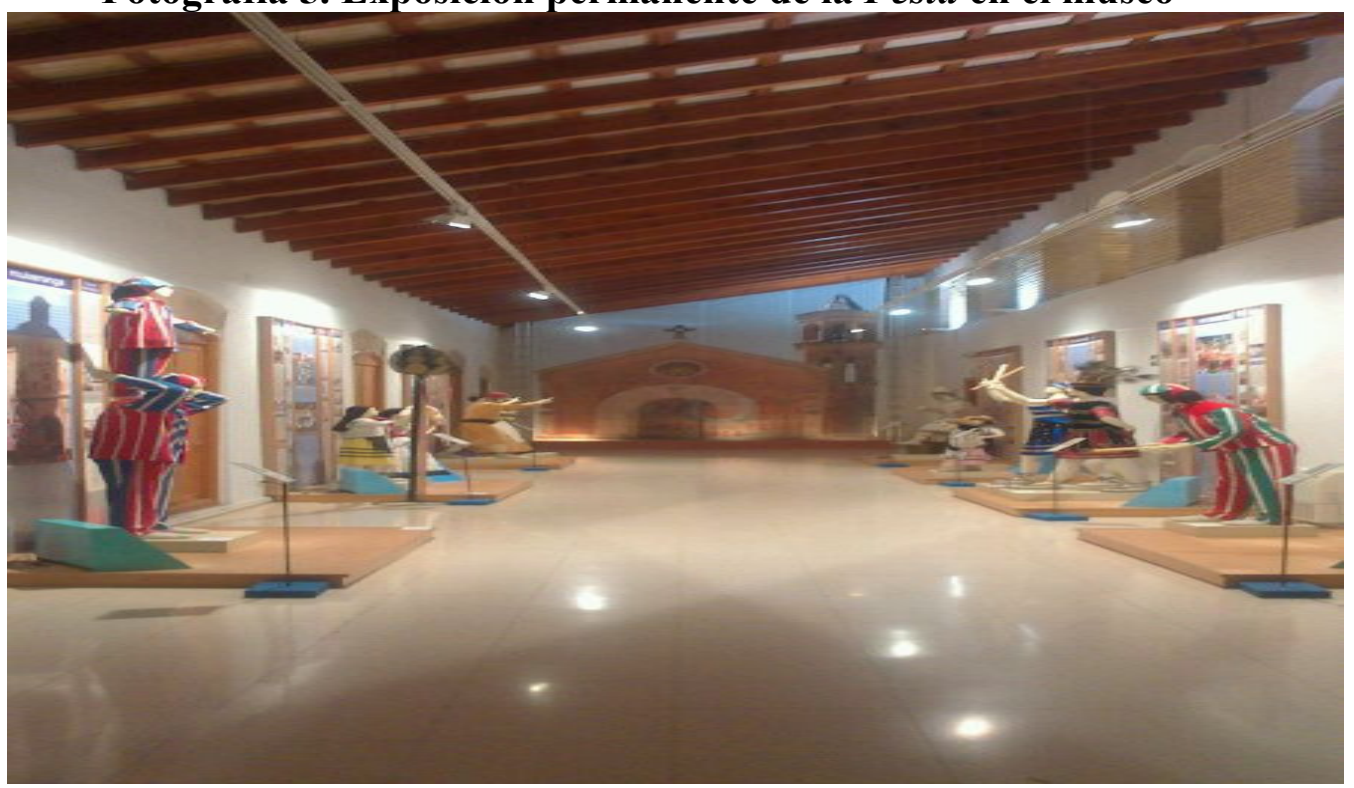

Autor: Antonio Bellón Climent. Marzo de 2014.

El Museu Valencià de la Festa ha realizado diferentes exposiciones, tanto a escala nacional como internacional. Se realizó una exposición itinerante que estuvo en diferentes ciudades rusas y ucranianas, como San Petersburgo (en el Hermitage), Moscú, Ekaterimburgo, Cheliabinsk, Odessa y Kiev. Y luego ésta se ha cedido con carácter permanente a Ekaterimburgo. En 2006 se hizo una filmación para el Museo de Etnología de Osaka. Otros lugares del mundo destacados en los que se ha expuesto han sido Milán, Bruselas, Nimes, Marsella, Manila, París, Berlín, Londres, Buenos Aires, Gangneung o Dubrovnik. En 2012 el Museu de la Festa pasó a formar parte de la ICCN (Inter-City Intangible Cultural Cooperation Network), que es un organismo de la UNESCO que se encarga de la protección de los Patrimonios Inmateriales de la Humanidad y promueve la cooperación entre ellos.

\section{Reconocimientos obtenidos}

Esta tradición nació como la procesión de una calle (teniendo constancia documentada de ello en 1610), pasó a tener carácter local en el año 1680, convirtiéndose en 1880 en lo que es actualmente. En las últimas décadas de siglo XX superó las fronteras locales, sobre todo con el resurgimiento de la Muixeranga. Ha venido ampliando su ámbito, primero a escala regional, para en los últimos años aumentar su proyección, primero a ámbito nacional, y ahora mundial.

Los principales reconocimientos obtenidos:

- 1977: Fiesta de Interés Turístico por el Ministerio de Economía.

- 2008: Una de las 7 maravillas de la Comunidad Valenciana.

- 2009: Uno de los 10 Tesoros del Patrimonio Cultural Inmaterial de España. 
- 2010: Bien de Interés Cultural por la Generalitat Valenciana.

- 2011: Patrimonio Inmaterial de la Humanidad por la UNESCO.

- 2012: Distinción al Mérito Cultural por la Generalitat Valenciana.

Las "7 Maravillas de la Comunidad Valenciana" son unas nominaciones, que surgen de la iniciativa que tuvieron la agencia de viajes Fil per Randa y la Academia Valenciana de la Llengua, con el patrocinio de Caixa Popular, y son las siguientes:

-Mare de Déu de la Salut y Muixeranga

-Parque Natural de la Albufera, El Saler y El Palmar

-Castillo y conjunto de Játiva

-Puerta del palacio Marqués de Dos Aguas de Valencia

-Peñal de Ifach

-Lonja de Valencia

-Estación del Norte de Valencia

Cada una representa a una categoría. Se eligieron ocho candidatas para cada una de ellas, y mediante votación popular se eligió a la ganadora. La Fiesta viene a representar a la que hace referencia a los acontecimientos culturales y patrimonio inmaterial, quedando por delante de las Sociedades Musicales de la Comunidad Valenciana, el Misteri d'Elx y el Tribunal de las Aguas.

Los "10 Tesoros del Patrimonio Cultural Inmaterial" es una promoción del patrimonio intangible en España, que realizó el Bureau Internacional de Capitales Culturales (IBOCC) en el año 2009, donde de una lista de cuarenta y cinco candidatos por elección ciudadana se elegían diez. Los elegidos fueron, por número de votaciones ${ }^{7}$ :

- Aste Nagusia de Bilbao

- Filandón de León

- Camino de Santiago

- Procesión de la Mare de Déu de la Salut de Algemesí

- Leyenda de los amantes de Teruel

- Fallas de Valencia

- Tradición de la Virgen del Pilar de Zaragoza

- Leyenda del Lagarto de la Malena de Jaén

- Carnaval de Cádiz

- Bienal de Flamenco de Sevilla

De los diez es la única celebración que no es de una ciudad importante. Se obtuvo mucho apoyo en las votaciones de gente valenciana muy identificada con esta celebración, y de los Castells catalanes. Este hecho le hizo ser noticia en muchos medios de información, y fue cuando el mundo de la cultura puso los ojos en esta localidad y en esta tradición, y su apuesta para su candidatura a Patrimonio Inmaterial de la Humanidad.

En el 2010 fue declarada por el Consell de la Generalitat Valenciana como Bien de Interés Cultural mediante el Decreto 117/2010, de 27 de agosto, que es el máximo reconocimiento institucional valenciano.

\footnotetext{
${ }^{7}$ Para más información, consultar: http://www.ibocc.org/news.php?ref=81.
} 
Según la UNESCO, el patrimonio cultural inmaterial comprende «tradiciones o expresiones vivas heredadas de nuestros antepasados y transmitidas a nuestros descendientes», y que éstas deben ser realizadas y mantenidas por una comunidad. El obtener este reconocimiento, a una tradición le permite preservar este valor intangible frente a las nuevas pautas y acciones de la sociedad actual que pueden dañarla, haciéndole perder así su singularidad. Esta organización también dice que debe interrelacionar culturas y respetar a todas las existentes. Y la festividad de Algemesí manifiesta todas esas condiciones, pues respeta a todos ellas, pues en sí misma es una interrelación y herencia de los diferentes pueblos que han vivido en estas tierras, pues sus danzas son herencia elementos cristianos, árabes y judíos, y de diferentes clases sociales como son burguesía, albañiles y agricultores.

Este municipio vivió su momento más importante y álgido el 28 de noviembre de 2011 , cuando recibió la denominación de Patrimonio Inmaterial de la Humanidad, en Bali (Indonesia). Con ello ha pasado de ser una fiesta de ámbito local a una de valor global. Para conmemorar esta designación, se le dedicó una celebración de carácter extraordinario el día 8 de diciembre de 2011 en la Plaça Major, en el que actuaron todos los elementos de la procesión y en el que la patrona fue sacada de la Basílica.

Por otra parte, el Pleno del Consell de la Generalitat Valenciana, decidió otorgar la Distinción al Mérito Cultural, que fue recibida el 9 de octubre (día de la Comunidad Valenciana) de 2012 en el Palacio de Benicarló, sede de las Cortes Valencianas.

Es de destacar el respeto que sienten los Castells por la Muixeranga, aspecto que ha provocado que éstos y las Fiestas de la Mare de Déu de la Salut se hayan hermanado recientemente. Para ver importancia que ha tenido ésta para el municipio y su festividad, constatar que «l'expressió de la Muixeranga d'Algemesí va més enllà dels límits locals. La seua projecció simbólica i geográfica es veu reflectida clarament en dos aspectos: l'apreci que per ella té tot el poblé valencia $i$ el sentimient que, per motiu d'antecedència i origen, mostra cap a ella el món casteller » (Alcaraz, 2004, p. 146). En marzo de 2014, la "Blava" recibió el premio "Ambaixador de Castells".

Por último, cabe destacar el reconocimiento que le otorgó la UNESCO al Museu Valencià de la Festa en 2012 por la labor que realiza de promoción internacional.

\section{¿QUÉ EFECTOS PUEDE GENERAR EL TURISMO TRAS LA DECLARACIÓN COMO PATRIMONIO DE LA HUMANIDAD?}

En este apartado se analiza cuáles son los puntos fuertes de esta celebración, que son muchísimos, y éstos todavía han aumentado más tras la declaración de la UNESCO. Pero también hay que señalar que también existen debilidades, que principalmente son dos: una capacidad de carga pequeña y una planta de alojamiento nula. Por último se analiza la dialéctica que puede surgir entre el respeto a la tradición y entre el hecho de realizar modificaciones con el objetivo de aprovechar económicamente el tirón que supone el ser Patrimonio Inmaterial de la Humanidad. 


\section{Puntos fuertes y puntos débiles}

Quizá la mayor potencialidad que tiene esta fiesta, a su vez se puede convertir en su mayor riesgo. Esta consiste en que la declaración como Patrimonio de la Humanidad es una imagen de marca que beneficia a la celebración y al municipio, pero que está a su vez es un riesgo, pues puede hacer que se modifiquen los patrones de comportamiento que se había llevado hasta el momento. Hasta hoy se ha apostado por la calidad en contra de cantidad, de forma que se ha evitado la banalización, cosa que provocaría la perdida de la peculiaridad, autenticidad y singularidad de esta tradición, y evitando la degradación de este patrimonio inmaterial. Pero esto último es uno de los peligros que puede tener, que tras esta designación y el gran aumento de interés por parte de fuera, se podría caer en el error de hacer cambios de cara a la gente y agentes alóctonos, convirtiéndola en una celebración masificada y perdiendo su atractivo. Se ha generado una imagen atractiva que a diferencia de otras tradiciones que encontramos en nuestra cultura, se ha mantenido basándose en el aspecto cualitativo, y no en el cuantitativo, es decir no en el incremento indefinido de la capacidad de acogida, pues aquí el elemento más destacado de la festividad, es que se basa en su singularidad. La gente hace las procesiones para el pueblo, pues es "su fiesta".

Una de las características de ésta, es que se celebra el día 8, pues tiene un carácter cíclico. Esto repercute en que al tener una fecha fija sobre el calendario, puede caer en cualquier día de la semana, pues va rotando, y esto afecta a las personas de la localidad que trabajan en otra ciudad y también a los visitantes, pues no en todos los municipios el 8 de septiembre es festivo. De igual manera este hecho tiene influencia en la Processó de Volta General, tanto para la gente local como la forastera, pues ésta termina a altas horas de la madrugada, y a no ser que ese año el día patronal caiga en viernes o sábado, la jornada siguiente es laboral.

Entre las mayores potencialidades tras la declaración de Patrimonio Inmaterial de la Humanidad cabe destacar el aumento del número de visitantes, cosa que se ha podido comprobar en estos dos últimos años (aunque matizado en que ambos ha caído en fin de semana). La mayoría de ellos viene con vehículo particular. Para ello se habilitan áreas de parking para que éstos puedan aparcar su automóvil. Éstas se sitúan en espacios amplios, como son los alrededores de la estación de ferrocarril o el matadero (éste se encuentra bastante alejado del centro histórico). También se realizan visitas organizadas para los días de las procesiones, pero a través de agentes externos. La Tourist Info de Algemesí le muestra información a estas agencias, y ellas se encargan de la gestión. Se ha habilitado el Colegio Maristas como parking para autobuses. En cuanto a la procedencia de estos visitantes cabe destacar la llegada de viajes organizados desde otros puntos de la Comunidad Valenciana, como también de extranjeros, la mayoría de ellos europeos, destacando los franceses, alemanes e ingleses. También han venido turistas de Corea y Japón. No existe un registro oficial para contabilizar el número de visitantes, el único son las visitas al museo que se realizan en los días 7 y 8 de septiembre. También la Policía Local contabiliza las entradas y salidas de automóviles en el municipio, aunque no es un método fiable. Según Julio Blasco, con los datos obtenidos entre ambos procedimientos se estima que el número de población que ha llegado al municipio en estos dos últimos años, en el tiempo que han durado las celebraciones en cada uno de ellos, ha podido multiplicar por cinco al número de habitantes de la localidad. 
Pero cuando más ha destacado ese aumento del número de visitantes ha sido en la Processoneta del Matí, que es de las tres, la que recibe mayor cantidad de población alóctona, mientras que en las otras dos no es tan elevado este contingente de personas forasteras. Los propietarios de pubs con los que se ha hablado coinciden en ese aspecto, en que han visto aumentar el "lleno" tanto de caja como de personas en su establecimiento en esa fecha respecto a años anteriores. También cabe citar que ha habido un factor que ha contribuido a este hecho, y es que ha tenido la coincidencia de que estos dos últimos años, el día 8 ha caído en sábado y en domingo respectivamente. Ahora la cuestión será ver si en este año y los siguientes, que el día patronal caerá entre semana, la afluencia de forasteros será tan masiva como en estos últimos, aunque cabe decir que se observa un positivismo en la opinión de los propietarios de estos negocios que creen que este factor no tendrá ninguna influencia.

Una debilidad es la falta de alojamientos en el municipio, debido a que esta localidad no es un destino turístico, debido a su situación geográfica, pues no se encuentra en el litoral. Pero cuando llegan las Fiestas de la Mare de Déu de la Salut, se convierte en un hervidero de visitantes. En un principio, éstos eran a nivel comarcal, pero poco a poco, y sobre todo en los últimos años y más aún tras ser declarado como Patrimonio Inmaterial de la Humanidad, ha aumentado la distancia del foco emisor. Pero tenemos que hablar en su mayor medida de excursionistas, que no turistas, pues no pernoctan. Los pocos que lo hacen, es en casa de familiares o amigos. La planta de alojamiento en el municipio es nula, pues sólo hay dos hostales, y los hoteles más cercanos los encontramos en Alcira, que se encuentra a $4 \mathrm{~km}$. Esto afecta al demandante potencialmente captable. La realización de éstos, podría generar un problema sobredimensión de infraestructuras para cubrir la demanda que se podría generar en las fechas cumbre, es decir 7 y 8 de septiembre, y unas semanas después en la Semana Taurina que también atrae a público forastero, pero el problema aparecería de tenerlas subutilizadas durante el resto del año.

La otra gran debilidad es que la capacidad de carga es escasa, hecho que guarda relación con el propio trazado de las procesiones, que se realizan en el centro histórico, con calles estrechas e irregulares. Es una fiesta realizada por y para el pueblo de Algemesí, donde existe una fuerte idiosincrasia con el recorrido de cada una de las tres procesiones, con un fuerte simbolismo en cada uno de ellas. Esto hace que para el público sea difícil encontrar sitio para ver los diferentes actos, sobre todo en aquellas calles más apretadas, como por ejemplo en la calle Berca durante la Processoneta del Matí, pero por otra parte este hecho también hace que la emoción del espectador de estar a una escasa distancia de la danza que está en ese momento actuando y de la música sea mucho mayor, pues le puede hacer sentirse casi un participante más. Lo que ocurre es que como se ha dicho anteriormente, es un festividad hecha por y para la propia gente del municipio, porque es "su fiesta" y existe una enorme carga sentimental alrededor de ésta, y su realización nunca ha estado pensada para la llegada de visitantes, pero que debido a su pervivencia en el tiempo y a su enorme valor inmaterial, despertó el interés alóctono hace unas décadas, viéndose incrementado de forma exagerada con todas las distinciones que ha recibido en los últimos años. La fiesta no está preparada para acoger a más visitantes debido a las propias características endógenas, y para paliar este problema ha surgido una propuesta que se analizará más adelante. Creo que el hecho de realizar cambios para ampliar la capacidad de carga rompería esta singularidad que tiene la festividad, y que es junto con la continuidad en el tiempo y su belleza plástica y acústica lo que le ha hecho ser reconocida por diferentes instituciones. 


\section{Entre el negocio local y el Patrimonio Mundial}

La fiesta ha contribuido a la actividad de algunos pequeños negocios, situados en el centro histórico, donde hay que destacar principalmente la Joieria Sant Sebastià, situada en la calle del mismo nombre, en la cual realizan figuras artesanas de semiporcelana de elementos que representan a la fiesta. Comenzaron a realizar estas figuras en el año 1972, registrándose en 1980 con la marca La Muixeranga. Estas se caracterizan porque están hechas manualmente, por tanto son piezas únicas, como se puede apreciar en que ninguna es igual a otra, primando el aspecto cualitativo sobre cuantitativo. Han obtenido diversos premios de artesanía. Venden por encargo a muchos países. En la actualidad no tienen mucha venta a nivel local, debido a que al ser piezas de alta cualidad tienen alto precio y también porque tras el prestigio adquirido por la festividad en los últimos años, otros negocios están comenzando a realizar figuras, aunque en este caso de menor calidad, pero a un precio menor ${ }^{8}$.

Como se ha comentado anteriormente, se produce un aprovechamiento de los recursos de ocio existentes en el municipio, formados por pubs y cafés, localizados en el centro histórico, de enorme interés para algunos grupos de demanda, como son los jóvenes, y que generan durante estos dos días flujos de visitantes de este tipo de población con origen en municipios cercanos, y que con el pretexto de ver una tradición cultural con prestigio pasar una "noche de fiesta", principalmente el día 7, pues en algunos municipios cercanos el día 8 es festivo debido a que también tienen como patrona una "Mare de Déu trobada", o si cae en fin de semana ese año no existe la necesidad de este factor, aumentando así la llegada de jóvenes ese año. Durante el mes de septiembre, que es la temporada alta, con estos dos días y unas semanas después con la Semana Taurina, también en honor de la Mare de Déu de la Salut, "los bares, pubs y restaurantes hacen el agosto", pues es cuando más ingresos consiguen.

Debido a la masiva afluencia de visitantes en estos dos últimos años, ha surgido el debate en las redes sociales de si sería conveniente invertir el recorrido de la Processó de Volta General, con el objetivo de evitar aglomeraciones en algunos puntos de aquellas calles que se recorren más temprano, pues suelen ser las más estrechas, mientras que las últimas del recorrido son las más anchas (Nou del Convent y Muntanya), y ahí se encuentra el verdadero objetivo, que sería ampliar el negocio de alquiler de sillas, aprovechando la anchura y extensión de la calle Muntanya, pues cuando más público alóctono hay es al principio de la procesión, pues no hay que olvidar que muchos años el día 8 coincide con un día laboral, y ésta termina a altas horas. El objetivo de esta medida sería aumentar los beneficios, pues las sillas hasta ahora se ponían en las calles estrechas, es decir, las conocidas como "carrers de volta", $\mathrm{y}$ que son las primeras por donde circula la procesión. Esta propuesta ha creado una dialéctica entre los vecinos de estos viarios, los cuales tienen un alto valor de precio debido a que por ellos pasa el seguicio procesional, y algunos agentes encargados de la organización de la fiesta, que pretenden generar más capacidad de carga para poder aumentar los ingresos con el negocio del alquiler de sillas.

\footnotetext{
${ }^{8}$ Se ha utilizado la técnica cualitativa de la conversación con Luis Manuel Caballero, Doctor en Bellas Artes por la Universidad Politécnica de Valencia y propietario de este pequeño taller de artesanía.
} 
Estoy de acuerdo en que hay que aprovechar la imagen de marca que genera el ser considerado como Patrimonio de la Humanidad e intentar con ello aumentar los beneficios económicos, pero no a costa de cambiar la tradición, pues esta festividad "ha llegado a ser lo que es", por mantenerse fiel a sí misma en el último siglo, pese a haber vividos muchos momentos de crisis. Si se invirtiera el recorrido por ganar capacidad de carga, estaríamos hablando de masificar la fiesta, cosa que le haría perder su autenticidad.

El Decreto 117/2010, de 27 de agosto, del Consell, por el que se declara Bien de Interés Cultural Inmaterial esta celebración, señala en su artículo 3.1. que «se establece como medida de protección que cualquier cambio en la Festa de la Mare de Déu de la Salut que exceda del normal desarrollo de los actos de la festividad anual, deba ser propuesto por la parroquia de San Jaime Apóstol o por el Patronato de la Fundació per a la Festa a la Mare de Déu de la Salut $i$ al Crist de l'Agonía a la Dirección General de Patrimonio Cultural Valenciano para, en su caso, autorización administrativa y consiguiente modificación del presente Decreto». En mi opinión, de la misma forma que se habla de que es una fiesta en la que participa todo el pueblo bien de forma activa o bien de forma pasiva, como así lo es, la decisión de sí invertir el itinerario debería ser tomada a través de la participación ciudadana mediante consulta (vinculante o no vinculante), ya que es un método democrático, que tendría una implicación de gran parte de los ciudadanos de este municipio, y el Patronato sabría cuál es la opinión de los vecinos, pues la idiosincrasia de la población local con el recorrido y con "su fiesta" es enorme. Se ha realizado una consulta en la red social de Facebook, pero esta no resulta transparente, pues no toda la población local tiene conocimiento de ella, ni de este debate, y por ello si realmente fuese necesario plantear alguna medida, ésta se tendría que proponer a través de algún medio que pudiese ver y fuera accesible a toda la población de la localidad, como en un BIM Berca, que es la revista local y llega a todas las casas.

\section{CONCLUSIONES}

Cuenta la tradición que las raíces de la morera fueron enterradas debajo de la casa número 38 de la calle Berca, pero realmente ésta no se enterró en 1683, pues cada una estas danzas que han pervivido en el tiempo, junto a la música, el sonido de las campanas, los festeros y todos los elementos que participan en las procesiones, sumado a toda la gente que acude como público, que son las diversas ramas de esa morera, árbol con 767 años y que debido a su longevidad, manteniendo sus tradiciones ha visto como ha sido reconocido por la UNESCO y diversas instituciones. Lo más característico de esta festividad, es la participación de gran parte de la población de un municipio en "su fiesta", que ha conseguido preservar y potenciar algunos de los hechos culturales con más historia de la cultura valenciana, y que en los días de celebración las calles se convierten en un museo con vida y movimiento.

Esta celebración es única y ha conseguido mantenerse virgen. Se debería aprovechar el tirón que genera de cara al turismo la designación como Patrimonio Inmaterial de la Humanidad, pues esos días muchos pequeños negocios locales, como bares y restaurantes, incrementan sus ingresos de forma considerable, debido al aumento del número de visitantes. 
Pero por otra parte, el municipio no está preparado para todo este turismo que se ha generado tras esta designación. El problema de la falta de alojamientos, es un aspecto que difícilmente se podrá paliar, pues si se construyesen infraestructuras hoteleras para este fin, tendrían que estar subutilizadas el resto del año, y no resultarían rentables. La propuesta de invertir el itinerario para albergar a más público forastero no es la solución a un espacio con una capacidad de carga pequeña, y en el que es cierto que en algunos puntos se produce congestión. De realizarse esta idea que está surgiendo de invertir el recorrido la procesión larga, realmente lo que se estaría produciendo es la perdida de esa identidad de la población local hacia el itinerario de ésta, pues además éste realiza un circuito contrario al de todas las procesiones que se hacen a lo largo del año, lo que le da un carácter de mayor importancia frente a las demás.

Es de destacar la labor de proyección que ha realizado el Museu Valencia de la Festa, que ha sido un agente clave para el hecho de ser hoy lo que es esta festividad. No solo ha sido importante el hecho de disponer de las dependencias en el propio municipio, sino con la realización de diversas exposiciones tanto temporales como permanentes, por diferentes partes del planeta, exportando el nombre de Algemesí por gran parte de la geografía mundial.

Por otra parte, el desconocimiento hacía esta celebración de gran cantidad de población nacional, y más grave aún de personas que son valencianas, es un hecho que denota la falta de difusión y apoyo (hasta hace nada) que ha tenido por parte de los medios de información y comunicación valencianos, que no de las instituciones, siendo el ejemplo más destacable la desaparecida televisión autonómica valenciana de Canal 9, y que como se ha visto en esta investigación, esta tradición es uno de los mayores patrimonios inmateriales de la cultura valenciana, debido a su preservación y continuidad en el tiempo, junto con su singularidad y riqueza plástica, visual y acústica. Por ello sería conveniente que otro canal de televisión tomase el relevo a la medida que tomó el año pasado Canal 9 con la retransmisión de estas procesiones.

\section{BIBLIOGRAFÍA}

ALCARAZ, A. Un món de muixerangues. Algemesí: Ajuntament de Algemesí, 2004, $156 \mathrm{p}$.

ATIENZA, A. La Procesión de la "Mare de Déu de la Salut" de Algemesí. Revista Folklore, Fundación Joaquín Díaz, 1991, nº 30, p.111-120.

ATIENZA, A. La Procesión de la "Mare de Déu de la Salut" de Algemesí. Revista Folklore, 1991, no 30, p. 120-134.

BALlESTER, B. Historia de la Villa de Algemesí. Algemesí: Ajuntament d'Algemesí, 2001, 203 p.

CANO, E. Músiques i Rituals a la Festes de la Mare de Déu de la Salut. Algemesí: Ajuntament d'Algemesí, 2004, 112 p.

CIPRIÀ, T. Viure, enmalaltir $i$ morir en l'Algemesí contemporani. Algemesí: Ajuntament d'Algemesí, 2007, 309 p. 
DOMINGO, B. Els dipositaris de la festa de la Mare de Déu. Revista Berca BIM, 1993, $\mathrm{n}^{\mathrm{o}} 51$.

DOMINGO, J. Festa a la Ribera: Les Festes d'Algemesí. Algemesí: Ajuntament d'Algemesí, 1983, 141 p.

DOMINGO, J. Bastint la Festa. Algemesí: Ajuntament d’ Algemesí, 1999, 100 p.

DOMINGO, J. Carrers de volta. Algemesí: Ajuntament d’Algemesí, 2004, 109 p.

DOMINGO, J. Nomenclátor. Algemesí: Ajuntament d’Algemesí, 2006, 108 p.

ESCARTÍ, V. Historia de l'aparició i troballa de la Mare de Déu de la Salut. Algemesí: Ajuntament d'Algemesí, 2006, 141 p.

ESTRELA, J. Els privilegis de la independencia d'Algemesí (segles XVI-XVII). Valencia: SAO, 1999, 109 p.

FERRER, E. Les figures de la Muixeranga. Algemesí: La Nova Muixeranga d'Algemesí, $20 \mathrm{p}$.

FERRI, A. La Mare de Déu de la Salut d’Algemesí. Algemesí: Basílica Parròquia de Sant Jaume Apòstol, 2004, 306 p.

FERRIS, V. Pintura mural a l'església de Sant Jaume d'Algemesí. Valencia: SAO, 1999, $141 \mathrm{p}$.

GREGORI, E. et al. La muixeranga d'Algemesí. Algemesí: Associació Amics de la Muixeranga, 1997, $93 \mathrm{p}$.

MORENO, A., ROIG, E. y OLIVARES, E. El bolero d'Algemesí: Cent anys del Ball de les Llauradores, Algemesí: Ajuntament d'Algemesí, 2006, 149 p.

OLIVARES, E. El campanar de Sant Jaume d'Algemesí: 1703-2003. Algemesí: Ajuntament d'Algemesí, 2003, 30 p.

OLIVARES, E. Cerámica devocional urbana d'Algemesí. Algemesí: Ajuntament d'Algemesí, 2003, 111 p.

RICHART, X. Estudiant la dolçaina: Tècnica i expressió. Valencia: Rivera, 2007, $216 \mathrm{p}$.

ROSSELLÓ, V. Cincuanta-cinc ciutats valencianes. Valencia: Universitat de Valencia, $1984,280 \mathrm{p}$.

TERUEL, J. Lloances a la Mare de Déu: Vida, teatre i tradició en les festes majors d'Algemesí. Valencia: SAO, 1997, 394 p.

TODOLÍ, A. Modernisme i Algemesí. Valencia: SAO, 2000, 455 p.

VIADEL, F. A l'ombra d'un campanar: Algemesi 1703-2003. Algemesí: Ajuntament d'Algemesí, 2003, 16 p. 


\section{RECURSOS ELECTRÓNICOS}

Academia Valenciana de la Llengua. <http://www.avl.gva.es/>. [03 de abril 2014].

Algemesí en la Memoria. <http://algemesienlamemoria.blogspot.com.es/>. [15 de abril 2014].

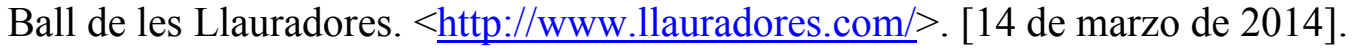

Bureau Internacional de Capitales Culturales. <http://www.ibocc.org/>. [22 de abril 2014].

Escola Municipal de Tabalet i Dolçaina. <http://www.emtid.org/>. [15 de abril 2014].

Fiestas de la Mare de Déu de Algemesí. <http://www.festesalgemesi.com/>. [14 de marzo 2014].

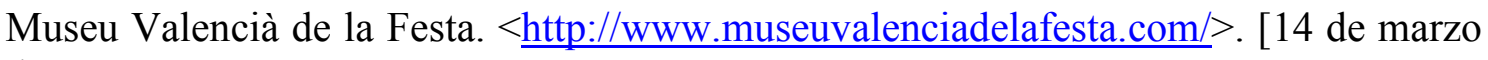
de 2014].

Muixeranga d'Algemesí. <http://www.muixeranga.net/>. [6 de abril de2014].

Nova Muixeranga d'Algemesí. <http://www.novamuixeranga.com/>. [6 de abril de 2014].

Periòdic Local Digital. < http://www.algemesiweb.es/tag/mare-de-deu-de-la-salut/>. [14 de marzo de 2014].

UNESCO. $<\underline{\text { http://www.unesco.org/> }}$ [14 de marzo de 2014].

(C) Copyright Antonio Bellón Climent, 2015.

(C) Copyright GeoGraphos, 2015.

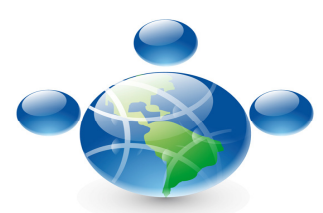

